\title{
Quantification and image-derived phenotyping of retinal ganglion cell nuclei in the nee
} mouse model of congenital glaucoma

Carly J. van der Heide ${ }^{\mathrm{\S}}$, Kacie J. Meyer ${ }^{\mathrm{a}}$, Adam Hedberg-Buenz ${ }^{\mathrm{a}, \mathrm{b}}$, Danielle Pellack ${ }^{\mathrm{a}}$, Nicholas

10 a Department of Molecular Physiology and Biophysics, University of lowa, 51 Newton Rd., lowa

11 City, IA 52242; 'VA Center for the Prevention and Treatment of Visual Loss, lowa City VA

12 Health Care System, 601 Hwy 6 West (151), lowa City, IA 52246; 'Department of

13 Ophthalmology and Visual Sciences, University of lowa, 200 Hawkins Dr., lowa City, IA 52242

15 §qual contribution

$17{ }^{*}$ Corresponding author: Dr. Michael G. Anderson, Department of Molecular Physiology and

18 Biophysics, 3123 Medical Education and Research Facility, 375 Newton Road, lowa City, IA

19 52242, (319) 355-7839 (telephone), (319) 335-7330 (FAX), michael-g-anderson@uiowa.edu

21 Author email addresses: Dr. Carly J. van der Heide, carly-vanderheide@uiowa.edu; Dr. Kacie J.

22 Meyer, kacie-meyer@uiowa.edu; Dr. Adam Hedberg-Buenz, adam-hedberg-buenz@uiowa.edu;

23 Danielle Pellack, danielle.pellack@gmail.com; Nicholas Pomernackas, nicholas-

24 pomernackas@uiowa.edu; Hannah E. Mercer, hbaker0123@gmail.com

26 The authors declare no competing financial interests. 


\section{ABSTRACT}

The nee mouse model exhibits characteristic features of congenital glaucoma, a common cause of childhood blindness. The current study of nee mice had two components.

First, the time course of neurodegeneration in nee retinal flat-mounts was studied over time using a retinal ganglion cell (RGC)-marker, BRN3A; a pan-nuclear marker, TO-PRO-3; and H\&E staining. Based on segmentation of nuclei using ImageJ and RetFM-J, this analysis identified a rapid loss of $B R N 3 A^{+}$nuclei from 4-15 weeks of age, with the first statistically significant difference in average density compared to age-matched controls detected in 8-week-old cohorts (49\% reduction in nee). Consistent with a model of glaucoma, no reductions in BRN3A- nuclei were detected, but the combined analysis indicated that some RGCs lost BRN3A marker expression prior to actual cell loss. These results have a practical application in the design of experiments using nee mice to study mechanisms or potential therapies for congenital glaucoma. The second component of the study pertains to a discovery-based analysis of the large amount of image data with 748,782 segmented retinal nuclei. Using the automatedly

41 collected region of interest feature data captured by ImageJ, we tested whether RGC density of

42 glaucomatous mice was significantly correlated to average nuclear area, perimeter, Feret

43 diameter, or MinFeret diameter. These results pointed to two events influencing nuclear size.

44 For variations in RGC density above approximately 3,000 nuclei/mm² apparent spreading was

45 observed, in which $\mathrm{BRN}^{-} \mathrm{A}^{-}$nuclei-regardless of genotype-became slightly larger as RGC

46 density decreased. This same spreading occurred in $\mathrm{BRN}^{+} \mathrm{A}^{+}$nuclei of wild-type mice. For

47 variation in RGC density below 3,000 nuclei/ $\mathrm{mm}^{2}$, which only occurred in glaucomatous nee

48 mutants, $\mathrm{BRN} \mathrm{A}^{+}$nuclei became smaller as disease was progressively severe. These

49 observations have relevance to defining RGCs of relatively higher sensitivity to glaucomatous

50 cell death and the nuclear dynamics occurring during their demise. 
bioRxiv preprint doi: https://doi.org/10.1101/2021.04.13.439698; this version posted September 23, 2021. The copyright holder for this preprint (which was not certified by peer review) is the author/funder, who has granted bioRxiv a license to display the preprint in perpetuity. It is made available under aCC-BY-NC-ND 4.0 International license.

52 KEY WORDS: retinal ganglion cells; glaucoma; mouse; retina; cell nucleus; displaced amacrine

53 cells; image segmentation; cell counter 


\section{1. Introduction}

Mice homozygous for the spontaneously arising $S h 3 p x d 2 b^{n e e}$ mutation (i.e. nee mice)

57 exhibit anterior segment dysgenesis and features of severe congenital glaucoma. In two

58 different genetic backgrounds, the original C57BL/10-related and a congenic C57BL/6J

59 background, nee mice develop high intraocular pressure (IOP) followed by retinal ganglion cell

60 (RGC) loss which is profound by 3 months of age (Daniel et al., 2019; Mao et al., 2011). Along

61 with congenital glaucoma, nee mice exhibit craniofacial, cardiac and skeletal abnormalities that

62 recapitulate Frank-Ter Haar syndrome (Mao et al., 2009), a rare human disease caused by

63 recessive mutations in the homologous gene, SH3PXD2B (lqbal et al., 2010). Thus, nee mice

64 directly model a known cause of glaucoma in humans. The manifestation of glaucoma in nee

65 mice is also notable among animal models of glaucoma because the disease is spontaneous,

66 severe, and fully penetrant (Mao et al., 2011), which are all experimental advantages.

While RGC loss in nee mice is known to be relatively severe and early onset, refining the

68 precise time-course of RGC loss in nee could uncover new insights and is a prerequisite

69 needed to inform the design of many future experiments, such as utilizing the nee model in tests

70 of neuroprotective agents. To achieve this, we have characterized the progression of RGC

71 death in young nee mice using ImageJ in a high-throughput image analysis technique that

72 quantified thousands of cell nuclei in the inner retina of each mouse retina. In addition to

73 providing counts of RGC nuclei, our image analysis data included information about the size

74 and shape of nuclei. In a discovery-based approach, we used these data to explore whether

75 RGC density of glaucomatous mice was significantly correlated to average nuclear area,

76 perimeter, Feret diameter, or MinFeret diameter. Combined, the results identify ages past 8

77 weeks as having statistically detectable differences in RGC density, identify a caveat regarding

78 loss of RGC marker expression prior to RGC cell loss in some cells of nee mice, and point to 
79 the possible ways in which automatedly collected image data can be used to discover new

80 disease-associated phenotypes.

81

\section{Materials and methods}

\subsection{Animal Husbandry}

87 (Daniel et al., 2019). The nee strain was maintained in heterozygote $\mathrm{X}$ heterozygote

88 intercrosses, with littermates homozygous for the mutant (abbreviated throughout as "nee") or

89 wild-type (abbreviated throughout as "WT") alleles primarily utilized in this study. As indicated in

90 the text, the SD-OCT imaging study utilized both WT and heterozygous mice (referred to as

91 "non-mutant", abbreviated throughout as "non-mut") to increase the sample size of controls.

92 Mice were housed at the University of lowa Animal Research Animal Facility, where they were

93 maintained on a $4 \%$ fat NIH 31 diet provided ad libitum, housed in cages containing dry bedding

94 (Cellu-dri; Shepherd Specialty Papers, Kalamazoo, MI), and kept in a $21^{\circ} \mathrm{C}$ environment with a

95 12-h light: 12-h dark cycle. All experiments included both male and female mice. All mice were

96 treated in accordance with the Association for Research in Vision and Ophthalmology

97 Statement for the Use of Animals in Ophthalmic and Vision Research. All experimental

98 protocols were approved by the Institutional Animal Care and Use Committee of the University 99 of lowa.

Mice were euthanized using $\mathrm{CO}_{2}$ asphyxiation followed by cervical dislocation and eyes

104 were immediately placed in cold 4\% paraformaldehyde for 10 minutes. Posterior cups were 
dissected in PBS and replaced in cold 4\% paraformaldehyde for 1 hour. Posterior cups were washed with PBS, and permeabilized with $0.3 \%$ Triton-X 100 in PBS (PBST) overnight at $37^{\circ} \mathrm{C}$. All subsequent steps were carried out at room temperature unless otherwise specified. Posterior cups were incubated in $3 \% \mathrm{H}_{2} \mathrm{O}_{2}-1 \% \mathrm{NaHPO}_{4}$ for 2 minutes and then retinas were dissected in PBS. Retinas were replaced in $3 \% \mathrm{H}_{2} \mathrm{O}_{2}-1 \% \mathrm{NaHPO}_{4}$ for 1 hour. Retinas were washed with PBST three times for 15 minutes, and then further permeabilized with PBST at $-80^{\circ} \mathrm{C}$ for 15 minutes. Retinas were washed again with PBST twice for 15 minutes, then blocked with $2 \%$ normal donkey serum in PBST overnight at $4^{\circ} \mathrm{C}$. Retinas were then incubated in primary

113 antibody (additional details noted in paragraph below) in PBS with $2 \%$ normal donkey serum,

$1141 \%$ Triton-X 100, and $1 \%$ DMSO (primary buffer) for two overnights at $4^{\circ} \mathrm{C}$. Retinas were

115 washed for 5 minutes in PBS with $2 \%$ Triton X-100, then washed further with PBST four times

116 for 15 minutes. Then retinas were incubated in secondary antibody (additional details below)

117 diluted in PBS with 5\% normal donkey serum, 1\% Triton-X 100, and 1\% DMSO (secondary

118 buffer). Retinas were washed twice for 15 minutes in PBST, then incubated in $1 \mu \mathrm{M}$ TO-PRO-3

119 (T3605; Thermo Fisher Scientific, Waltham, MA) in PBS for 15 minutes, and washed again with

120 PBST three times for 15 minutes. Retinas were then washed briefly with PBS and mounted

121 using Aqua-Mount (Lerner, Pittsburgh, PA). Individual retinas that were studied by both

122 immunolabeling and hematoxylin/eosin (H\&E) staining were labeled as described above,

123 followed by soaking off coverslips by submersion of the slide in distilled water. H\&E staining was

124 performed under the following conditions: hematoxylin (1 minute), rinse in double-distilled water,

125 acid alcohol (3 seconds), rinse in water, 80\% ethanol (1 minute), eosin (2 seconds), 95\%

126 ethanol (30 seconds), 100\% ethanol (30 seconds), and xylenes (twice for 30 seconds each

127 time). MM 24 mounting media (Leica, Wetzlar, Germany) was used to apply coverslips to slides.

128 Different antibody combinations were applied to the protocol (as described above) for

129 two distinct purposes. For the purpose of RGC quantification, retinas were incubated in a

130 polyclonal goat anti-BRN3A antibody (C-20, 1 :200; Santa Cruz Biotechnology, Dallas, TX) 
131 diluted in primary buffer for two overnights at $4^{\circ} \mathrm{C}$ followed by incubation in a donkey anti-goat

132 Alexa 488-conjugated secondary antibody (A11055, 1:200; Life Technologies, Madison, WI)

133 diluted in secondary buffer for three hours at room temperature. For the purpose of testing for

134 potential marker-specific effects in quantifying RGCs, retinas were incubated in the anti-BRN3A

135 and a polyclonal rabbit anti-RBPMS antibody (GTX118619, 1:1,000; GeneTex, Irvine, CA)

136 diluted in primary buffer for two and four overnights at $4^{\circ} \mathrm{C}$, respectively. Retinas underwent two

137 sequential treatments in secondary antibodies diluted in secondary buffer, including an

138 incubation in the donkey anti-goat Alexa 488-conjugated secondary antibody as indicated above

139 and then in a donkey anti-rabbit Alexa 546-conjugated secondary antibody (A10040, 1:500; Life

140 Technologies, Madison, WI) overnight at $4^{\circ} \mathrm{C}$.

2.3 Microscopy and quantification of nuclei in the inner retina

Immunolabeled retinas were photographed using a Zeiss LSM710 confocal microscope

145 (Carl Zeiss, Oberkochen, Germany). Images were collected at 538X total magnification

$146\left(1024 \times 1024 \mathrm{px}, 0.18 \mathrm{~mm}^{2}\right.$ image area) from non-overlapping fields at each of three zones of

147 eccentricity ( $n=12$ images total: 4 central, 4 mid-peripheral, 4 peripheral). Photos were

148 captured in a single plane of focus at the level of the RGC layer. Images were processed in

149 ImageJ with the Enhance Local Contrast (CLAHE) process (blocksize 125, histogram bins 256,

150 maximum set to 3 for BRN3A-labeled images and maximum set to 10 for TO-PRO3-labeled

151 images), the Subtract Background tool with rolling ball radius set to 35 pixels for BRN3A and 20

152 pixels for TO-PRO-3, followed by the Smooth tool. The TO-PRO-3 images were additionally

153 processed with Gaussian blur (sigma set to 0.5) and the Enhance contrast process with $10 \%$

154 saturated pixels and application of histogram equalization. Images were then converted to

155 binary using Huang thresholding. Binary images were further processed using the Open,

156 Watershed, and Fill Holes functions. To count BRN3A+ nuclei, the Analyze Particles function 
157 was applied to the BRN3A images with particle size set to $38-150 \mu \mathrm{m}^{2}$ and circularity $0.55-1$.

158 The segmentation of $\mathrm{BRN} \mathrm{A}^{+}$nuclei was saved as a region of interest and subtracted from the

159 TO-PRO-3 images. Then, the Analyze Particles function was applied to TO-PRO-3 images with

160 size set to $20-150 \mu \mathrm{m}^{2}$ and circularity of $0.4-1$ to quantify the BRN3A', TO-PRO-3+ population.

161 The metrics quantified with the Analyze Particles function are defined by ImageJ as follows:

162 "Area" refers to the area of the selection in square pixels, calibrated to square microns;

163 "Perimeter" refers to the length of the outside boundary of the selection; "Feret diameter" refers

164 to the longest distance between any two points along the selection boundary, a.k.a. maximum

165 caliper; "MinFeret diameter" refers to the minimum caliper. Individual retinas that were studied

166 by both immunolabeling and H\&E staining were photographed and quantified as described

167 above, followed by H\&E staining and imaging with a light microscope (BX52; Olympus, Tokyo,

168 Japan) equipped with a digital camera (DP72; Olympus, Tokyo, Japan). H\&E-stained nuclei

169 were quantified with RetFM-J as previously described (Hedberg-Buenz et al., 2016c).

170 In testing for the possibility of marker-specific results, an independent set of retinas

171 immunolabeled for both BRN3A and RBPMS were imaged as described above. Four images,

172 including two from the peripheral and mid-peripheral zones of retina were randomly selected for

173 manual quantification of cells immunolabeled by each marker using the "cell counter" tool of

174 ImageJ $\{$ Schneider, $2012 \# 1\}$ by an investigator blinded to the identity of each image (i.e.

175 genotype of mouse the retina was collected from, retinal zone, etc.). All images were viewed by

176 the investigator in single-channel format, and therefore single-marker, to ensure that cell

177 detection and counting is done using the signal emitted by only one marker at a time. Results

178 were expressed in terms of cell number and compared across markers using a Bland Altman

179 plot and coefficient of determination $\left(R^{2}\right)$.

180 
8-week-old mice received an intraperitoneal injection of a mixture of ketamine/xylazine

184 (87.5 mg/kg Ketamine (VetaKetß), AKORN, Lake Forest, IL)/12.5 mg/kg Xylazine (Anased,

185 Lloyd Laboratories $\AA$, Shenandoah, IA). Upon anesthesia, eyes were hydrated with balanced

186 salt solution (BSS; Alcon Laboratories, Fort Worth, TX). To obtain retinal images, the tear film

187 was wicked away and eyes were imaged with a Bioptigen spectral domain optical coherence

188 tomographer (SD-OCT; Bioptigen, USA) using the mouse retinal bore. The volume intensity

189 projection was centered on the optic nerve. Following imaging, eyes were hydrated with

190 lubricant ophthalmic ointment (Artificial Tears, AKORN, Lake Forest, IL) and mice were provided

191 supplemental indirect warmth for anesthesia recovery. Retinal ganglion cell complex (RGCC;

192 inner limiting membrane to the innermost border of the inner nuclear layer) thickness was

193 measured from retinal images within the Bioptigen InVivoVue Clinic software four times per eye

194 using vertical angle-locked B-scan calipers.

2.5 Optic nerve collection, histology, and quantification

8-week-old mice were euthanized by carbon dioxide inhalation with death confirmed by cervical spine dislocation. Optic nerves were collected, processed for histology, stained,

200 imaged, and quantified as previously described (Mao et al., 2011; Trantow et al., 2009). Mouse

201 heads were fixed in half-strength Karnovsky's fixative for a minimum of 24 hours. Nerves were

202 then dissected and embedded in resin. Histologic sections were cut using an ultramicrotome

203 (UC6, Leica, Wetzler, German) equipped with a diamond knife (Histo, Diatome, Hatfield, PA,

204 USA), stained with paraphenylenediamine (PPD; (Anderson et al., 2005)), and imaged using a

205 light microscope (BX52; Olympus, Tokyo, Japan) equipped with a camera (DP72; Olympus,

206 Tokyo, Japan) and corresponding software (CellSens; Olympus, Tokyo, Japan). Cross-sectional

207 area of the optic nerve was measured using ImageJ. Axons were counted from 6-10 non- 
overlapping fields at $1000 \mathrm{X}$ magnification representing $10 \%$ of the optic nerve cross-sectional area. The total number of axons for each nerve was estimated by multiplying the sum of the axons in the counted fields by 10 .

\subsection{Statistics}

215 multiple comparisons using Sidak's multiple comparisons test with a single pooled variance.

216 Correlations were analyzed for significance using linear regression. Data comparing nuclear

217 area and retinal area were analyzed by multiple two-tailed Student's $t$-tests and corrected for

218 multiple comparisons using the two-stage step-up method of Benjamini, Krieger and Yekutieli.

219 The power calculations noted in the Discussion was performed using the Piface Java applet by

220 Russell V. Lenth (Lenth, 2006) with an analysis for two-sample $t$-test (pooled or Satterthwaite).

221 For the $\mathrm{BRN}^{+} \mathrm{A}^{+}$cell density, the power calculation assumptions entered are sigma1 $=794.2$

222 (standard deviation of nee $\mathrm{BRN}^{+} \mathrm{A}^{+}$cell density at 8 weeks old), sigma2 $=162.0$ (standard 223 deviation of WT BRN3A ${ }^{+}$cell density at 8 weeks old), alpha $=0.05$, true difference of means = $224870.2\left(50 \%\right.$ of the $\mathrm{BRN}^{+} \mathrm{A}^{+}$cell loss in nee mice at 8 weeks old compared to WT littermates), 225 power $=0.8981$, and solving for sample size. For the retinal ganglion cell complex (RGCC)

226 thicknesses measured by OCT, the power calculation assumptions entered are sigma1 $=14.3$

227 (standard deviation of nee RGCC thickness at 8 weeks old), sigma2 $=1.7$ (standard deviation of 228 non-mut RGCC thickness at 8 weeks old), true difference of means $=11.7(50 \%$ of the RGCC 229 thickness decrease in nee mice at 8 weeks old compared to non-mut littermates), power = 2300.9019 , and solving for sample size. For the optic nerve cross-sectional area, the power 231 calculation assumptions entered are sigma1 $=0.007$ (standard deviation of nee cross-sectional 232 area at 8 weeks old), sigma2 $=0.026$ (standard deviation of the WT cross-sectional area at 8 233 weeks old), alpha $=0.05$, true difference of means $=0.022$ (50\% of the optic nerve cross- 
234 sectional area loss in nee mice at 8 weeks old compared to WT littermates), power $=0.9084$,

235 and solving for sample size. For the optic nerve total axon number, the power calculation

236 assumptions entered are sigma1 $=5,325$ (standard deviation of nee optic nerve axon number at

2378 weeks old, sigma2 $=4,279$ (standard deviation of WT optic nerve axon number at 8 weeks

238 old), true difference of means $=8,884$ (25\% of the optic nerve axon number loss in nee mice at

2398 weeks old compared to WT littermates), power $=0.9256$, and solving for sample size. A two-

240 tailed Student's $t$-test was used to analyze data comparing nee-mutant mice vs. non-mutant

241 mice for OCT RGCC thickness, optic nerve cross-sectional area, and total axon number.

\section{3. Results}

\subsection{Severe RGC loss in nee mice by 8 weeks of age}

To refine the early progression of congenital glaucoma in nee mice, we quantified RGC

248 loss in nee and WT littermates from 4-15 weeks of age. Immunolabeling of retinal flat-mounts

249 with an anti-BRN3A antibody showed a progressive loss of BRN3A ${ }^{+}$RGCs (Fig. 1A). At 4 weeks

250 of age, quantified data showed a significant loss of BRN3A ${ }^{+}$nuclei in all retinas by 8 weeks of

251 age (Fig. 1B), whereby nee mice exhibited a 49\% reduction in the average density of BRN3A

252 nuclei $\left(1,801.2 \pm 794.2\right.$ nuclei $\left./ \mathrm{mm}^{2}\right)$ compared to WT littermates $\left(3,541.3 \pm 162.0 \mathrm{nuclei} / \mathrm{mm}^{2} ; \mathrm{p}\right.$

$253<0.05,2$-way ANOVA with Sidak's multiple comparisons correction). BRN3A ${ }^{+}$RGC densities in

254 nee mice younger than 8 weeks of age were highly variable, with some eyes severely affected

255 while others were not different from WT littermates. As a test for the possibility of marker-

256 specific results, an independent group of flat-mounts were simultaneously analyzed for BRN3A

257 and RBPMS immunolabeling (S. Fig. 1). The results again indicated a severe loss of RGCs

258 detectable by both markers in nee mice. Comparisons of the two markers were broadly 
congruent with one another, though RBPMS labeled more cells that BRN3A, particularly in severe disease.

To further evaluate nee mice as a model of glaucoma, we tested whether non-RGC cell

262 types die in nee retinas by quantifying nuclei labeled with TO-PRO-3 but negative for BRN3A

$263\left(\mathrm{BRN} \mathrm{A}^{-}\right)$. There was no reduction in the density of BRN3A- nuclei of nee mice in any age

264 group (Fig. 1C). Oddly, nee mice exhibited a 16\% higher density of BRN3A- nuclei at 15 weeks

$265\left(5,253.6 \pm 176.0\right.$ nuclei $\left./ \mathrm{mm}^{2}\right)$ compared to WT littermates $\left(4,393.4 \pm 142.3\right.$ nuclei $/ \mathrm{mm}^{2} \mathrm{p}=$

266 0.0004, 2-way ANOVA with Sidak's multiple comparisons correction). Suspecting that the

267 increased density of $\mathrm{BRN}^{-} \mathrm{A}^{-}$nuclei observed in nee mice was due to a loss of marker

268 expression, not cell loss, these retinas were stained with H\&E and nuclei of all cell types were

269 counted (Hedberg-Buenz et al., 2016c). In nee mice aged 4-8 weeks, there was a 21\%

270 reduction in the density of $\mathrm{BRN}^{+} \mathrm{A}^{+}$nuclei $\left(2,909 \pm 817\right.$ nuclei/mm $\left.{ }^{2}\right)$ compared to WT $(3,686 \pm$

271265 nuclei/mm²; $<<0.01 ; 2$-way ANOVA with Sidak's multiple comparisons correction), but the

272 density of total nuclei stained by H\&E exhibited no corresponding cell loss $(7,675 \pm 587$ in nee

273 vs $7,797 \pm 228$ nuclei/mm² in WT; Fig. 1D), a discrepancy that suggests loss of only BRN3A

274 immunoreactivity. Slightly older nee mice (12-15 weeks old) exhibited a $62.3 \%$ loss of BRN3A

275 RGCs $(1,299 \pm 873$ in nee vs 3,444 \pm 120 nuclei/mm² in WT; $p<0.0001 ; 2$-way ANOVA with

276 Sidak's multiple comparisons correction) along with a $18.5 \%$ decrease in total cells stained with

$277 \operatorname{H\& E}(6,373 \pm 646$ in nee vs $7,816 \pm 287$ nuclei/mm² in WT). Because RGCs constitute

278 approximately $41-50 \%$ of total RGC-layer cells in C57BL/6J mice (Jeon et al., 1998; Schlamp et

279 al., 2013), if only RGCs were lost, an 18.5\% decrease in total cells would correspond to a 37-

$28045 \%$ decrease in RGCs. The RGC loss we detected using BRN3A immunolabeling is $17-25 \%$

281 higher than the H\&E estimate, a difference similar to the $21 \%$ discrepancy we detected in the

282 younger cohort. Conclusively, we estimate that $\sim 20 \%$ of RGCs in glaucomatous nee mice stop

283 expressing BRN3A prior to actual RGC loss. 
Non-invasive in vivo imaging of the retina was performed in 8-week-old glaucomatous nee mice using SD-OCT. Corresponding to the severe loss of RGCs, the RGC complex is significantly thinner in 8-week-old nee mice $(n=6)$ compared to non-mutant (HET and WT

287 genotypes combined; $\mathrm{n}=5)$ littermates $(32.9 \pm 14.3 \mu \mathrm{m}$ vs. $56.3 \pm 1.7 \mu \mathrm{m} ; \mathrm{p}<0.01$; Student's

288 two-tailed $t$-test; Fig. 2A-C). We also observed differences in the appearance of optic nerve

289 head depth and the peripapillary retina. Retinas of nee mice typically had an overall normal

290 lamination, though 4 out of 21 retinas examined at 8 weeks of age had lamination abnormalities

291 and/or retinal rosettes. As a complementary approach, optic nerve cross-sectional area and

292 axon counts were quantified in 8-week-old nee mice (Fig. 2D-G). There was a significant

293 reduction in both optic nerve cross-sectional area $\left(0.050 \pm 0.007 \mathrm{~mm}^{2}\right.$ vs. $0.093 \pm 0.26 \mathrm{~mm}^{2} ; \mathrm{p}<$

294 0.001; Student's two-tailed $t$-test; Fig. 2F) and axon number (12,660 $\pm 5,326$ axons vs. 48,196 \pm

$2954,280$ axons; $p<0.001$; Student's two-tailed $t$-test; Fig. $2 \mathrm{G})$ in nee mice $(\mathrm{n}=8)$ compared to WT

296 littermates $(n=5)$.

3.2 Nuclear size characteristics of surviving $B R N 3 A^{+} R G C$ s decrease with increasing severity of glaucomatous damage in nee mice segmented retinal nuclei underlying our study of nee mice, we examined whether any of the feature parameters automatedly measured by ImageJ correlated to disease stage. Region of

304 interest feature data captured by ImageJ was averaged for each retina and tested for correlation 305 to $\mathrm{BRN}^{+} \mathrm{A}^{+}$cell density (Fig. 3). Three populations were considered: WT controls, nee retinas

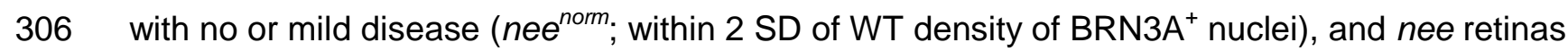
307 with moderate to severe disease (nee $e^{\text {mod-sev }} ;<2$ SD of WT density of BRN3A ${ }^{+}$nuclei).

Among BRN3A+ RGCs (Fig. 3A-D), WT retinas showed a significant correlation between 309 average nuclear area and density (Fig. 3A) in which average nuclear size slightly increased as 
310 density decreased across the normal range of densities $\left(3,238-4,203\right.$ nuclei $/ \mathrm{mm}^{2} ;$ mean $=$

$3113,577,1 \mathrm{SD}=241.5)$. Contrasting this, the RGCs of $n e e^{\text {mod-sev }}$ retinas showed an opposite trend

312 that was also significant, in which nuclei became progressively smaller on average as density

313 fell during disease. RGCs of nee ${ }^{\text {norm }}$ retinas had no detectable correlation between nuclear area

314 and density. Similar trends and statistical associations were detected in plots of $\mathrm{BRN} \mathrm{A}^{+}$density

315 versus nuclear perimeter (Fig. 3B), Feret diameter (Fig. 3C), and MinFeret diameter (Fig. 3D).

316 Among BRN3A- nuclei (Fig. 3E-H), WT retinas again showed a significant correlation between

317 average nuclear area and density (Fig. 3E) in which BRN3A- nuclei became slightly larger with

318 decreasing density of $\mathrm{BRN} \mathrm{A}^{+}$nuclei. Unlike RGCs, the BRN3A- population of nuclei in nee $e^{\text {mod- }}$

$319{ }^{\text {sev }}$ retinas showed no significant correlation to density. Also differing from RGCs, the BRN3A

320 population of nuclei in nee ${ }^{\text {norm }}$ retinas mirrored the trends of WT cells, with average nucleus size

321 slightly increasing as density decreased. Similar trends and statistical associations were

322 detected in plots of BRN3A- density versus nuclear perimeter (Fig. 3F), Feret diameter (Fig.

323 3G), and MinFeret diameter (Fig. 3H), with the sole exception of one association between

$324 \mathrm{BRN} \mathrm{A}^{-}$density and MinFeret diameter in nee $e^{\text {mod-sev }}$ retinas that met statistical significance with

325 a slim margin $(p=0.049)$. In sum, these results point to two events influencing nuclear size. In

326 almost all analyses (regardless of genotype or marker) there was a slight enlargement of nuclei

327 as RGC density decreased. At approximately 3,000 nuclei $/ \mathrm{mm}^{2}$ there was an inflection point in

328 the trend lines, below which only the population of viable RGC nuclei, but not $\mathrm{BRN} \mathrm{A}^{-}$cells, had

329 nuclei that became smaller as disease was progressively severe.

3.3 RGCs with small nuclei account for a greater proportion of the surviving population in severe

332 stages of nee glaucoma

We next sought to explore what phenomena might be causing the average nuclear size

335 to be decreasing through disease progression. First, we analyzed the population distribution of 


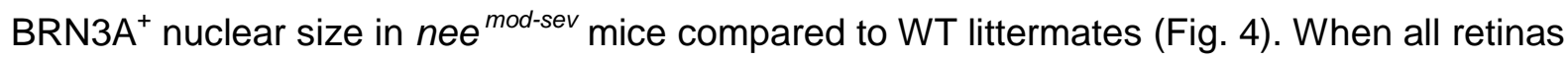
were grouped together, the average size of $\mathrm{BRN} \mathrm{A}^{+}$nuclei in nee ${ }^{\text {mod-sev }}$ retinas was $6.8 \%$ larger $\left(84.5 \pm 21.5 \mu \mathrm{m}^{2}\right)$ than WT $\left(79.1 \pm 18.3 \mu \mathrm{m}^{2} ; \mathrm{p}<1 \mathrm{E} 10^{-15} ;\right.$ Fig. $\left.4 \mathrm{~A}\right)$ presumably because many retinas with less severe RGC loss had an average nuclear size that was larger than WT (Fig. $4 \mathrm{~A}, \mathrm{~B})$. However, a limitation of combining data in this way was that the healthiest nee $e^{\text {mod-sev }}$

341 retinas, those with the greatest number of cells, were overrepresented. Thus, instead of

342 studying a size distribution for all retinas of a genotype together, we next analyzed distributions

343 for each retina individually.

345 with a preponderance of small nuclei but a long right-hand tail (Fig. 4C, E). In these retinas, the average $\mathrm{BRN}_{3} \mathrm{~A}^{+}$nuclear size was larger than the median in every case. An example of such a retina is indicated with a black arrowhead in Fig. 4 B\&C, in this instance a retina with 3,238 nuclear sizes of $80.9 \pm 18.1 \mu \mathrm{m}^{2}$ and $78.1 \mu \mathrm{m}^{2}$, respectively.

In contrast, the size distributions were highly variable among nee ${ }^{\text {mod-sev }}$ retinas. Some

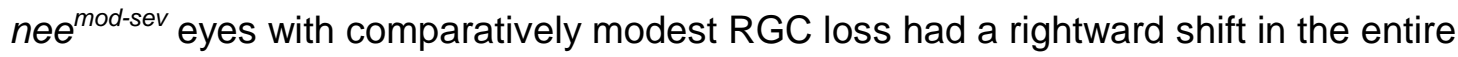

352 histogram, whereby there was an increase in both the median and the mean relative to WT, with 353 minimal change in the shape of the curve. An example is illustrated by the red arrowhead in Fig.

3544 B\&C. If the greater average nuclear size were caused by a preferential loss of smaller nuclei,

355 the left part of the curve would decrease, and the right side would reciprocally increase (note the

$356 \mathrm{Y}$ axis represents the percentage of total $\mathrm{BRN} \mathrm{A}^{+}$nuclei). Because the shape of the histogram

357 of this modestly affected eye only changed minimally while the entire curve was shifted

358 rightward, the increased average size was not a result of preferential loss of the smallest cells

359 and was more likely reflective of nuclear enlargement broadly occurring in most RGCs

360 regardless of their initial size. In severe disease, the shape of the histogram was markedly

361 different. Severely affected nee $e^{\text {mod-sev }}$ eyes had fewer large nuclei and a larger proportion of 
smaller RGCs. An example is illustrated by the red asterisk in Fig. 4 B\&C (in this instance, combining data from two severely affected retinas, from a single mouse, with very similar

$364 \mathrm{BRN} \mathrm{A}^{+}$densities—so that a larger number of nuclei, similar to the other comparisons, could be 365 considered). The right-hand tail of the curve was attenuated and there was a corresponding 366 reciprocal peak in the left-hand tail of the curve, representing an increased proportion of small

367 RGC nuclei relative to the total population. In this case, the smaller average nuclear size in 368 severely affected eyes reflected a greater proportion of small nuclei in the surviving RGC 369 population.

To test whether these differences in the nuclear size distribution were specific to RGCs,

371 we plotted histograms of $\mathrm{BRN} \mathrm{A}^{-}$nuclear size quantified from the same eyes and did not

372 observe as pronounced differences in histogram shape or position of the major peak (Fig. 4D).

373 As expected for a population likely consisting mostly of displaced amacrine cells (Drager and

374 Olsen, 1981; Janssen et al., 2013), the average size of BRN3A' nuclei was smaller than

$375 \quad \mathrm{BRN}^{+} \mathrm{A}^{+}$nuclei.

To broadly visualize how the shape of the nuclear size distributions related to disease

377 state, distributions were analyzed individually for all retinas and graphed in a box and whisker

378 plot (Fig. 4E). In this representation, every retina was normalized to its median to allow for

379 comparisons of the shape of the distribution. In WT retinas, the mean value was consistently

380 greater than the median, reflecting the long right-hand tail of the distribution. In contrast, many

381 nee ${ }^{\text {mod-sev }}$ retinas exhibited a smaller difference between the median and the mean, where the

382 mean was displaced leftward towards the median, suggesting an attenuated right-hand tail of

383 the curve and a greater proportion of smaller nuclei compared to the WT cell population. In

384 some nee ${ }^{\text {mod-sev }}$ retinas, the mean was displaced even farther to the left beyond the median,

385 signifying a longer left-tailed distribution with proportionately more RGC nuclei of small size. The

386 greater proportions of small nuclei in nee ${ }^{\text {mod-sev }}$ retinas was also indicated by a decrease in the

387 average of the $10^{\text {th }}, 25^{\text {th }}$ and $90^{\text {th }}$ percentile values of nee ${ }^{\text {mod-sev }}$ retinas compared to WT. 


\section{Discussion}

In this study with glaucomatous nee mice, ImageJ was used to quantify some traditional phenotypes commonly needed in studies of glaucoma (density of variously defined cell populations over time), as well as some novel phenotypes (size metrics for automatedly

394 detected regions of interest) whose relevance to glaucoma was unknown. The methodology for

395 RGC nuclei quantification has some elements of advancement within it, but the focus here has 396 been on its application.

The first component of the study was to study the time course of neurodegeneration in 398 nee retinal flat-mounts over time. These experiments indicated that nee mice have a $49 \%$ 399 reduction in $\mathrm{BRN} \mathrm{A}^{+} \mathrm{RGCs}$ by 8 weeks of age. No eyes escaped disease; every retina from 400 mice aged 8 weeks or older was affected. However, some cases of severely affected retinas 401 were already detectable at 4 weeks of age (our youngest cohort). While the early onset and 402 complete penetrance of glaucoma are advantage of the nee model for testing neuroprotective 403 therapies, it is important to recognize that the model does have some heterogeneity in age of 404 onset and treatments would presumably need to be initiated early. Based on the current 405 findings, initiation of treatments in newborn mice no later than 4 weeks of age appears 406 warranted, and in some cases, treating pregnant/nursing mothers may be advantageous. From 407 the BRN3A ${ }^{+}$cell densities measured in 8-week-old WT and nee mice, we can predict that a 408 neuroprotection of $50 \%$ of the RGCs otherwise expected to lose BRN3A marker expression 409 and/or die from glaucoma should be detectable with $90 \%$ power $(\alpha=0.05)$ using a two-tailed $t$ 410 test with cohorts of 11 samples per treatment group. From the RGCC thickness measured in 8411 week-old non-mut and nee mice, we can predict that RGCC thickness increases of $50 \%$ of the 412 thickness lost in nee mice should be detectable with $90 \%$ power $(\alpha=0.05)$ using a two-tailed $t$ 413 test with cohorts of 18 mice per sample group. From the optic nerve cross-sectional area 
414 measured in 8-week-old WT and nee mice, we can predict that optic nerve cross-sectional area

415 increases of $50 \%$ of the thickness lost in nee mice should be detectable with $90 \%$ power $(\alpha=$

416 0.05) using a two-tailed $t$-test with cohorts of 18 mice per sample group. From the optic nerve

417 axon counts quantified in 8-week-old WT and nee mice, we can predict that optic nerve axon

418 count increases of $25 \%$ of the number of axons lost in nee mice should be detectable with $90 \%$

419 power $(\alpha=0.05)$ using a two-tailed $t$-test with cohorts of 8 mice per sample group. Thus, tests of

420 neuroprotective agents for nee-mediated early onset glaucoma are feasible for this model by

421 quantifying $\mathrm{BRN}^{+} \mathrm{A}^{+}$cell density, using OCT to measure RGCC thickness, measuring optic

422 nerve cross-sectional area, and quantifying optic nerve axon numbers, with $B R N 3 A^{+}$cell density

423 and optic nerve axon counts requiring fewer mice and directly quantifying RGC loss. Since a

424 subset of RGCs in the nee model lose BRN3A expression prior to cell death, it is important to

425 note that this power calculation is specific to use of BRN3A to mark RGCs. Use of other RGC

426 markers may give different results depending on if or when RGCs lose marker expression prior

427 to cell death. Quantification of cells that are nuclear-marker positive and RGC-marker negative,

428 as well as use of $\mathrm{H} \& \mathrm{E}$ to count all retinal nuclei, can help parse loss of marker expression

429 versus cell death as we have done here for the BRN3A RGC marker. Measurement of the

430 RGCC via OCT requires more mice per cohort and is an indirect measurement of RGC loss but

431 is a non-invasive assay that has the benefit of providing same-animal longitudinal data.

432 Therefore, our current data should aid in the design of meaningful future experiments utilizing

433 the nee model of early onset glaucoma.

434 An additional insight gained through these experiments was that RGC quantification data

435 obtained from nee using immunolabeling techniques should be interpreted with caution. In our

436 study, we detected an appreciable loss of immunoreactivity in RGCs. Approximately $20 \%$ of

437 RGCs in nee mice aged 4-15 weeks lost BRN3A expression prior to cell death. This finding

438 aligns with previous reports of reduced gene expression in models of acute RGC injury (Huang

439 et al., 2006; Schlamp et al., 2001) and in DBA/2J mice (Soto et al., 2008). Accordingly, the 49\% 
reduction in RGC density detected in the 8-week-old nee cohort was probably an overestimate

441 of RGC loss-assuming $20 \%$ of the nuclei likely lost BRN3A immunoreactivity, the true degree

442 of RGC death was likely closer to $30 \%$. Importantly, no loss of BRN3A ${ }^{-}$nuclei was observed in

443 nee retinas. Sparing of non-RGC types is supportive of nee as a model of glaucoma, as

444 opposed to other types of retinal neurodegeneration not specific to RGCs. Many studies with

445 mouse models of glaucoma do not report the propensity for neuronal damage to non-RGC cell-

446 types in the inner retina, such as displaced amacrine cells (Pang and Clark, 2020), but the

447 specificity of RGC loss observed in nee mice do distinguish it from models based upon NMDA

448 excitotoxicity (Hama et al., 2008; Siliprandi et al., 1992) or retinal ischemia (Dijk and Kamphuis,

4492004 ; Ju and Kim, 2011) in which profound loss of other cell-types is known to occur.

450 Several mouse models relevant to early onset developmental forms of glaucoma have

451 been described (Akula et al., 2020; Chang et al., 2001; Chen and Gage, 2016; Ishibashi et al.,

452 1999; Iwao et al., 2009; Kroeber et al., 2010; Labelle-Dumais et al., 2020; Lachke et al., 2011;

453 Smith et al., 2000; Thomson et al., 2017; Tolman et al., 2021). Among them, many studies have

454 focused on phenotypes of the anterior segment and there have been relatively few in depth

455 studies of RGC damage. One exception, a detailed study by Daniel et al. (Daniel et al., 2019),

456 utilized nee mice to study the susceptibilities of 4 different RGC sub-types to glaucomatous

457 damage. The overall levels of RGC damage in the study by Daniel et al. were assessed with

458 NeuN immunolabeling (manual counting of 6-8 retinal flat-mounts per age; 8 sample regions

459 per retina, each $0.09 \mathrm{~mm}^{2} ; 4$ central and 4 peripheral) and detected a steady age-related

460 decline in RGC density with statistically significant differences as early as 30 days of age $(2,349$

$461 \pm 126 \mathrm{cell} / \mathrm{mm}^{2}$ in wild-type, which reduced to $1,785 \pm 161 \mathrm{cells} / \mathrm{mm}^{2}$ by day 30 in nee

462 homozygotes). In comparison to the current findings, which had different goals and used

463 different methodology (BRN3A immunolabeling; automated segmentation of 3-7 retinal flat-

464 mounts per age; 12 sample regions per retina, each $0.18 \mathrm{~mm}^{2}$; 4 central, 4 mid-peripheral, and

4654 peripheral), both studies detected an early onset glaucomatous loss of RGCs but the study by 
Daniel detected a statistically distinguishable loss earlier. Several factors likely contributed to

467 these slightly different findings. First, the current study used BRN3A immunolabeling, which we

468 found is lost in some RGCs prior to actual cell death, perhaps confounding an ability to detect

469 differences. Second, there were notable differences in total RGC densities, even among wild-

470 type controls between the two studies $\left(\sim 2,400\right.$ cells $/ \mathrm{mm}^{2}$, Daniel; $~ 3,600$ cells $/ \mathrm{mm}^{2}$, current

471 study), hinting that the study by Daniel had a greater emphasis on peripheral sites where RGC

472 densities are lowest.

473 The second component of the current study involved a discovery-based analysis of the

474 large amount of automatedly collected region of interest feature data captured by ImageJ. At the

475 outset, it was unclear whether subtle differences in these "phenotypes" would add any

476 information to understanding of glaucoma. At least hundreds, if not thousands, of previous

477 studies have undoubtedly qualitatively observed RGC nuclei and a few have measured nuclear

478 areas. In studying a much larger number of nuclei than practical manually, at a micron-level

479 which might surpass the ability of human observers to notice trends, the broadest question of

480 the current analysis was "would image-based phenotyping detect anything new?". The results

481 did detect significant trends, pointing to two events influencing nuclear size. In almost all

482 analyses (regardless of genotype or marker) there was a slight enlargement of nuclei as RGC

483 density decreased. At approximately 3,000 nuclei $/ \mathrm{mm}^{2}$ there was an inflection point in the trend

484 lines, below which only the population of viable RGC nuclei, but not BRN3A- cells, had nuclei

485 that became smaller as disease was progressively severe.

One event influencing nuclear size appears to be a passive "spreading out" of nuclei as

487 space allows. Spreading appears to have a predominant influence on nuclear area in retinas

488 with densities above 3,000 nuclei $/ \mathrm{mm}^{2}$. For most size-related parameters of $\mathrm{BRN}^{+} \mathrm{A}^{+}$and

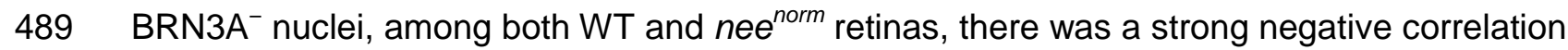

490 between nuclear size and cell density, whereby average nucleus size increased with decreasing

491 cell density. We speculate that under normal physiological conditions, neurons generally tend to 
492 be larger in retinas with lower cell densities because space is less confined. The only

493 exceptions to this finding were a single lack of significance for BRN3A ${ }^{+}$nuclei in WT retinas for

494 MinFeret diameter, and all four of the comparisons for $\mathrm{BRN}^{+} \mathrm{A}^{+}$nuclei in $n e e^{\text {norm }}$ retinas. Among

495 the $n e e^{\text {norm }}$ retinas, the lack of association might be explained by simultaneously competing

496 events, a passive spreading out as RGCs begin to be lost that tends to increase average

497 nuclear size, offset by a preferential loss of larger nuclei that tends to decrease average nuclear

498 size. The phenomenon of spreading appears to also be present in an anatomical context, where

499 RGC size is known to vary with respect to eccentricity. RGCs are significantly larger in the

500 peripheral retina, an area of relatively low cell density compared to the central retina, where

501 RGCs are smaller and more numerous (Drager and Olsen, 1981; Urcola et al., 2006). RGC

502 enlargement in some stages of disease has been previously observed in multiple studies (Davis

503 et al., 2020; Hedberg-Buenz et al., 2016a; Moore and Thanos, 1996; Urcola et al., 2006). For

504 example, among surviving RGCs in a rat model of chronic IOP elevation induced by microbead

505 injection (Urcola et al., 2006), in which a loss of $27.2 \%$ of RGCs after 24 weeks led to a $11.9 \%$

506 increase in RGC somal area-a subtle change in size in response to modest changes in RGC

507 density similar to those observed here. Urcola et al. described this as "hypertrophy". Because

508 RGC somal and nuclear areas have previously been shown to be positively correlated (Davis et

509 al., 2020; Janssen et al., 2013), it seems likely that the "hypertrophy" observed by Urcola et al,

510 and "spreading" described here, are the same phenomenon. Davis et al. (Davis et al., 2020)

511 observed RGC nuclear enlargement in the early stages following partial optic nerve transection

512 and hypothesized that it might involve metabolic responses of the injured RGCs. Because we

513 have observed spreading in not only glaucomatous RGCs, but also in non-RGCs of mice with

514 glaucoma and in RGCs of healthy WT mice, we propose a more passive response-though

515 future studies to study this phenomenon are needed.

516 A second event influencing nuclear size appears to be a preferential loss of larger RGC

517 nuclei through progressive stages of glaucoma. For only BRN3A ${ }^{+}$nuclei of nee ${ }^{\text {mod-sev }}$ retinas, 
518 there was a strong positive correlation with RGC nuclear size, whereby average nucleus size

519 decreased with decreasing cell density. This phenomenon was specific to RGCs and not

520 detected among $\mathrm{BRN} \mathrm{A}^{-}$nuclei. In examining size distribution plots, the RGC population in

521 glaucomatous retinas was markedly different from WT retinas and highly dependent on disease

522 stage. Healthy WT retinas consistently exhibited a right-skewed distribution of $\mathrm{BRN}^{+} \mathrm{A}^{+}$nuclear

523 size, in which the average RGC size was always greater than the median, and the right-hand

524 side of the distribution curve had a long tail. In retinas with modest glaucoma, there was

525 rightward displacement of the entire distribution curve, reflecting an indiscriminate enlargement

526 of RGC nuclei of all size. In retinas with advanced glaucoma there was an attenuation of the

527 right-hand tail of the size distribution, in some cases becoming a left-skewed distribution, and

528 there was often a second peak in the left-hand tail, indicating an enlarged fraction of small RGC

529 nuclei.

We speculate that the biological basis for greater proportions of small RGC nuclei in

531 eyes with severe disease may involve nuclear atrophy and/or size-selective vulnerability to

532 glaucoma. Some aspects of apoptosis are rapid events, with multiple studies identifying active

533 apoptosis in only $<1-15 \%$ of RGCs at any given time (reviewed in (Cordeiro et al., 2011); thus,

534 many apoptotic events are likely too transient to significantly impact the population average for

535 nuclear size. In contrast, nuclear atrophy driven by histone deacetylase activity is a sustained

536 event that can precede BAX-dependent apoptosis in RGCs (Janssen et al., 2013; Schmitt et al.,

537 2016). In mouse models of optic nerve crush, nuclear atrophy appears within 24 hours, is

538 maximal at 5 days, and persistent thereafter (Janssen et al., 2013). In comparison to other

539 events occurring with optic nerve crush, nuclear atrophy precedes both apoptotic nuclear

540 fragmentation, which typically begins at days 5-7 post-injury, and cell death, which typically

541 begins after day 10 post-injury (Li et al., 1999). Thus, nuclear atrophy is a sustained event that

542 could contribute to our current observations with nee mice. Alternatively, average RGC size

543 could decrease with progressive disease because the largest cells are preferentially dying. 
544 Preferential vulnerability of larger RGCs has been a long-standing hypothesis in glaucoma

545 (Glovinsky et al., 1991; Vickers et al., 1995; Wang et al., 2020), and in mice, has been

546 supported by an enrichment of small RGCs in old DBA/2J mice with late-onset glaucoma

547 (Buckingham et al., 2008; Hedberg-Buenz et al., 2016a). The current results establish that this

548 is also the case for nee mice with early onset congenital glaucoma.

549 There are caveats to consider in the interpretation of these data. First, immunolabeling

550 was used to quantify only BRN3A $A^{+}$RCs because it labels the nucleus, lending itself nicely to

551 the semi-automated high-throughput segmentation approach used here. Accordingly, the data

552 most specifically relate to the surviving RGC population that still expresses BRN3A. Although

553 Brn3a appears to be transcribed in all sub-classes of RGCs (Rheaume et al., 2018), most

554 studies find that immunolabeling fails to identify some ( 3-15\%) RGCs (Davis et al., 2020;

555 Galindo-Romero et al., 2011; Rodriguez et al., 2014). Thus, RGCs that either lost, or never had,

556 detectable BRN3A were potentially confounding. For example, many melanopsin containing

557 RGCs are not well-labeled by BRN3A (Sanchez-Migallon et al., 2018; Valiente-Soriano et al.,

558 2014). Because melanopsin-containing RGCs are relatively rare ( 2-3\% of the total RGC

559 population) (Valiente-Soriano et al., 2014), these cells likely had a miniscule impact on our

560 overall findings. Non-RGC cell-types were only studied in aggregate, not with additional specific

561 markers. This may be of relevance because a subtle loss of displaced amacrine cells that are

562 coupled to RGCs via gap junctions has been reported in a microbead-induced model of

563 glaucoma (Akopian et al., 2019). Our current experimental design, lacking specific markers of

564 displaced amacrine cells and complicated by RGCs losing BRN3A expression, was not well-

565 matched for detection of this event—-though it would be an interesting area for future work using

566 nee mice. Second, with 40+ sub-types of RGCs now molecularly recognized (Rheaume et al.,

567 2018; Tran et al., 2019), it is probable that nuclear size may be a susceptibility-factor for many

568 RGCs, but other sub-type specific factors could also play a role (Tran et al., 2019; Wang et al.,

569 2020). Melanopsin-containing RGCs, which are somewhat resistant to multiple forms of damage 
570 (Cui et al., 2015; Daniel et al., 2019; Jakobs et al., 2005; Li et al., 2006; Sanchez-Migallon et al.,

571 2018), are often described as an exception to the "larger = more susceptible" hypothesis,

572 perhaps incorrectly, as their soma are actually small to average in size and only their dendritic

573 field is comparatively large (Berson et al., 2010; Coombs et al., 2006; Xiao et al., 2021). In

574 future work, it could be informative to elucidate the molecular events which drive the association

575 of smaller nuclei with RGC survival.

576 In sum, this study has quantified the severe loss of RGCs in the nee mouse model of

577 congenital glaucoma and used a large amount of simultaneously collected image data related to

578 nuclear size to phenotype glaucomatous mice in a new way. The results point to competing

579 events influencing nuclear size, with spreading of multiple cell types occurring with modest

580 decreases in RGC density and a preferential loss of large RGC nuclei in moderate to severe

581 cases of RGC loss due to glaucoma. Given the progress in refining approaches using

582 automated image analysis to quantify RGC soma (Danias et al., 2006; Dordea et al., 2016;

583 Guymer et al., 2020; Hedberg-Buenz et al., 2016a; Hedberg-Buenz et al., 2016b; Masin et al.,

584 2021; Salinas-Navarro et al., 2009) and axons (Bosco et al., 2015; Mysona et al., 2020;

585 Reynaud et al., 2012; Ritch et al., 2020; Teixeira et al., 2014; Zarei et al., 2016) it appears that

586 the approach that we, and others (Davis et al., 2020), have begun to utilize to phenotype RGCs

587 in these automated ways may make additional discoveries. Although studies to date have

588 analyzed only a small number of parameters that were all related to nuclear size, future

589 experiments could likewise analyze many additional features, some of which may also be

590 beyond the practical limit for humans to have been led to suspect as important based only on

591 visual observation.

592

\section{ACKNOWLEDGEMENTS}

594 This work was supported in part by Merit Review Award (I01 RX001481) from the U.S.

595 Department of Veterans Affairs RR\&D Service and an NIH/NEI Center Support Grant to the 
University of lowa (P30 EY025580). AHB was supported by Training Grant Award

(T32DK112751). The funding sources had no involvement in study design; in the collection,

analysis and interpretation of data; in the writing of the report; or in the decision to submit the

article for publication. The contents do not represent the views of the U.S. Department of

600 Veterans Affairs or the U.S. Government.

\section{REFERENCES}

603 Akopian, A., Kumar, S., Ramakrishnan, H., Viswanathan, S., Bloomfield, S.A., 2019. Amacrine cells coupled to ganglion cells via gap junctions are highly vulnerable in glaucomatous mouse retinas. The Journal of comparative neurology 527, 159-173.

Akula, M., Taiyab, A., Deschamps, P., Yee, S., Ball, A.K., Williams, T., West-Mays, J.A., 2020. AP-2beta is required for formation of the murine trabecular meshwork and Schlemm's canal. Exp Eye Res 195, 108042. Anderson, M.G., Libby, R.T., Gould, D.B., Smith, R.S., John, S.W., 2005. High-dose radiation with bone marrow transfer prevents neurodegeneration in an inherited glaucoma. Proc Natl Acad Sci U S A 102, 4566-4571. Berson, D.M., Castrucci, A.M., Provencio, I., 2010. Morphology and mosaics of melanopsinexpressing retinal ganglion cell types in mice. The Journal of comparative neurology 518, 24052422.

Bosco, A., Romero, C.O., Breen, K.T., Chagovetz, A.A., Steele, M.R., Ambati, B.K., Vetter, M.L., 2015. Neurodegeneration severity can be predicted from early microglia alterations monitored in vivo in a mouse model of chronic glaucoma. Dis Model Mech 8, 443-455. Buckingham, B.P., Inman, D.M., Lambert, W., Oglesby, E., Calkins, D.J., Steele, M.R., Vetter, M.L., Marsh-Armstrong, N., Horner, P.J., 2008. Progressive ganglion cell degeneration precedes neuronal loss in a mouse model of glaucoma. Journal of Neuroscience 28, 27352744.

Chang, B., Smith, R.S., Peters, M., Savinova, O.V., Hawes, N.L., Zabaleta, A., Nusinowitz, S., Martin, J.E., Davisson, M.L., Cepko, C.L., Hogan, B.L., John, S.W., 2001. Haploinsufficient Bmp4 ocular phenotypes include anterior segment dysgenesis with elevated intraocular pressure. BMC Genet 2, 18.

Chen, L., Gage, P.J., 2016. Heterozygous Pitx2 Null Mice Accurately Recapitulate the Ocular Features of Axenfeld-Rieger Syndrome and Congenital Glaucoma. Invest Ophthalmol Vis Sci 57, 5023-5030.

Coombs, J., van der List, D., Wang, G.Y., Chalupa, L.M., 2006. Morphological properties of mouse retinal ganglion cells. Neuroscience 140, 123-136.

Cordeiro, M.F., Migdal, C., Bloom, P., Fitzke, F.W., Moss, S.E., 2011. Imaging apoptosis in the eye. Eye (Lond) 25, 545-553.

Cui, Q., Ren, C., Sollars, P.J., Pickard, G.E., So, K.F., 2015. The injury resistant ability of melanopsin-expressing intrinsically photosensitive retinal ganglion cells. Neuroscience 284, 845-853.

638 Danias, J., Shen, F., Kavalarakis, M., Chen, B., Goldblum, D., Lee, K., Zamora, M.-F., Su, Y., Podos, S.M., Mittag, T., 2006. Characterization of retinal damage in the episcleral vein cauterization rat glaucoma model. Exp Eye Res 82, 219-228. 
639 Daniel, S., Meyer, K.J., Clark, A.F., Anderson, M.G., McDowell, C.M., 2019. Effect of ocular

640

641

642

643

644

645

646

647

648

649

650

651

652

653

654

655

656

657

658

659

660

661

662

663

664

665

666

667

668

669

670

671

672

673

674

675

676

677

678

679

680

681

682

683

684

685

686

687

688 hypertension on the pattern of retinal ganglion cell subtype loss in a mouse model of early-onset glaucoma. Exp Eye Res 185, 107703.

Davis, B.M., Guo, L., Ravindran, N., Shamsher, E., Baekelandt, V., Mitchell, H., Bharath, A.A., De Groef, L., Cordeiro, M.F., 2020. Dynamic changes in cell size and corresponding cell fate after optic nerve injury. Sci Rep 10, 21683.

Dijk, F., Kamphuis, W., 2004. An immunocytochemical study on specific amacrine cell subpopulations in the rat retina after ischemia. Brain Res 1026, 205-217.

Dordea, A.C., Bray, M.-A., Allen, K., Logan, D.J., Fei, F., Malhotra, R., Gregory, M.S., Carpenter, A.E., Buys, E.S., 2016. An open-source computational tool to automatically quantify immunolabeled retinal ganglion cells. Exp Eye Res 147, 50-56.

Drager, U.C., Olsen, J.F., 1981. Ganglion cell distribution in the retina of the mouse. Invest Ophthalmol Vis Sci 20, 285-293.

Galindo-Romero, C., Aviles-Trigueros, M., Jimenez-Lopez, M., Valiente-Soriano, F.J., SalinasNavarro, M., Nadal-Nicolas, F., Villegas-Perez, M.P., Vidal-Sanz, M., Agudo-Barriuso, M., 2011. Axotomy-induced retinal ganglion cell death in adult mice: quantitative and topographic time course analyses. Exp Eye Res 92, 377-387.

Glovinsky, Y., Quigley, H.A., Dunkelberger, G.R., 1991. Retinal ganglion cell loss is size dependent in experimental glaucoma. Invest Ophthalmol Vis Sci 32, 484-491.

Guymer, C., Damp, L., Chidlow, G., Wood, J., Tang, Y.F., Casson, R., 2020. Software for quantifying and batch processing images of brn3a and RBPMS immunolabelled retinal ganglion cells in retinal wholemounts. Translational vision science \& technology 9, 28-28.

Hama, Y., Katsuki, H., Suminaka, C., Kume, T., Akaike, A., 2008. Chloride-dependent acute excitotoxicity in adult rat retinal ganglion cells. Neuropharmacology 55, 677-686.

Hedberg-Buenz, A., Christopher, M.A., Lewis, C.J., Fernandes, K.A., Dutca, L.M., Wang, K., Scheetz, T.E., Abràmoff, M.D., Libby, R.T., Garvin, M.K., 2016a. Quantitative measurement of retinal ganglion cell populations via histology-based random forest classification. Exp Eye Res 146, 370-385.

Hedberg-Buenz, A., Christopher, M.A., Lewis, C.J., Meyer, K.J., Rudd, D.S., Dutca, L.M., Wang, K., Garvin, M.K., Scheetz, T.E., Abràmoff, M.D., 2016b. RetFM-J, an ImageJ-based module for automated counting and quantifying features of nuclei in retinal whole-mounts. Exp Eye Res 146, 386-392.

Hedberg-Buenz, A., Christopher, M.A., Lewis, C.J., Meyer, K.J., Rudd, D.S., Dutca, L.M., Wang, K., Garvin, M.K., Scheetz, T.E., Abramoff, M.D., Harper, M.M., Anderson, M.G., 2016c. RetFM$\mathrm{J}$, an ImageJ-based module for automated counting and quantifying features of nuclei in retinal whole-mounts. Exp Eye Res 146, 386-392.

Huang, W., Fileta, J., Guo, Y., Grosskreutz, C.L., 2006. Downregulation of Thy1 in retinal ganglion cells in experimental glaucoma. Curr Eye Res 31, 265-271.

lqbal, Z., Cejudo-Martin, P., de Brouwer, A., van der Zwaag, B., Ruiz-Lozano, P., Scimia, M.C., Lindsey, J.D., Weinreb, R., Albrecht, B., Megarbane, A., Alanay, Y., Ben-Neriah, Z., Amenduni, M., Artuso, R., Veltman, J.A., van Beusekom, E., Oudakker, A., Millan, J.L., Hennekam, R., Hamel, B., Courtneidge, S.A., van Bokhoven, H., 2010. Disruption of the podosome adaptor protein TKS4 (SH3PXD2B) causes the skeletal dysplasia, eye, and cardiac abnormalities of Frank-Ter Haar Syndrome. Am J Hum Genet 86, 254-261.

Ishibashi, K., Yamamoto, H., Hatano, M., Koizumi, T., Yamamoto, M., Tokuhisa, T., 1999. Enlargement of the globe with ocular malformations in c-Myc transgenic mice. Jpn J Ophthalmol 43, 201-208.

Iwao, K., Inatani, M., Matsumoto, Y., Ogata-Iwao, M., Takihara, Y., Irie, F., Yamaguchi, Y., Okinami, S., Tanihara, H., 2009. Heparan sulfate deficiency leads to Peters anomaly in mice by disturbing neural crest TGF-beta2 signaling. J Clin Invest 119, 1997-2008. 
689

690

691

692

693

694

695

696

697

698

699

700

701

702

703

704

705

706

707

708

709

710

711

712

713

714

715

716

717

718

719

720

721

722

723

724

725

726

727

728

729

730

731

732

733

734

735

736

737

738

739

Jakobs, T.C., Libby, R.T., Ben, Y., John, S.W., Masland, R.H., 2005. Retinal ganglion cell degeneration is topological but not cell type specific in DBA/2J mice. The Journal of cell biology 171, 313-325.

Janssen, K.T., Mac Nair, C.E., Dietz, J.A., Schlamp, C.L., Nickells, R.W., 2013. Nuclear atrophy of retinal ganglion cells precedes the bax-dependent stage of apoptosis. Invest Ophthalmol Vis Sci 54, 1805-1815.

Jeon, C.J., Strettoi, E., Masland, R.H., 1998. The major cell populations of the mouse retina. J Neurosci 18, 8936-8946.

Ju, W.K., Kim, K.Y., 2011. Measuring glutamate receptor activation-induced apoptotic cell death in ischemic rat retina using the TUNEL assay. Methods Mol Biol 740, 149-156.

Kroeber, M., Davis, N., Holzmann, S., Kritzenberger, M., Shelah-Goraly, M., Ofri, R., Ashery-

Padan, R., Tamm, E.R., 2010. Reduced expression of Pax6 in lens and cornea of mutant mice leads to failure of chamber angle development and juvenile glaucoma. Hum Mol Genet 19, 3332-3342.

Labelle-Dumais, C., Pyatla, G., Paylakhi, S., Tolman, N.G., Hameed, S., Seymens, Y., Dang, E., Mandal, A.K., Senthil, S., Khanna, R.C., Kabra, M., Kaur, I., John, S.W.M., Chakrabarti, S., Nair, K.S., 2020. Loss of PRSS56 function leads to ocular angle defects and increased susceptibility to high intraocular pressure. Disease models \& mechanisms 13.

Lachke, S.A., Alkuraya, F.S., Kneeland, S.C., Ohn, T., Aboukhalil, A., Howell, G.R., Saadi, I., Cavallesco, R., Yue, Y., Tsai, A.C., Nair, K.S., Cosma, M.I., Smith, R.S., Hodges, E., Alfadhli, S.M., Al-Hajeri, A., Shamseldin, H.E., Behbehani, A., Hannon, G.J., Bulyk, M.L., Drack, A.V., Anderson, P.J., John, S.W., Maas, R.L., 2011. Mutations in the RNA granule component TDRD7 cause cataract and glaucoma. Science 331, 1571-1576.

Lenth, R.V., 2006. Java Applets for Power and Sample Size [Piface version 1.76 computer software]. Retrieved February 24, 2015 from http://www.stat.uiowa.edu/ rlenth/Power. Li, R.S., Chen, B.Y., Tay, D.K., Chan, H.H., Pu, M.L., So, K.F., 2006. Melanopsin-expressing retinal ganglion cells are more injury-resistant in a chronic ocular hypertension model. Invest Ophthalmol Vis Sci 47, 2951-2958.

Li, Y., Schlamp, C.L., Nickells, R.W., 1999. Experimental induction of retinal ganglion cell death in adult mice. Invest Ophthalmol Vis Sci 40, 1004-1008.

Mao, M., Hedberg-Buenz, A., Koehn, D., John, S.W., Anderson, M.G., 2011. Anterior segment dysgenesis and early-onset glaucoma in nee mice with mutation of Sh3pxd2b. Investigative ophthalmology \& visual science 52, 2679-2688.

Mao, M., Thedens, D.R., Chang, B., Harris, B.S., Zheng, Q.Y., Johnson, K.R., Donahue, L.R., Anderson, M.G., 2009. The podosomal-adaptor protein SH3PXD2B is essential for normal postnatal development. Mammalian genome : official journal of the International Mammalian Genome Society 20, 462-475.

Masin, L., Claes, M., Bergmans, S., Cools, L., Andries, L., Davis, B.M., Moons, L., De Groef, L., 2021. A novel retinal ganglion cell quantification tool based on deep learning. Scientific reports 11, 1-13.

Moore, S., Thanos, S., 1996. Differential increases in rat retinal ganglion cell size with various methods of optic nerve lesion. Neurosci Lett 207, 117-120.

Mysona, B.A., Segar, S., Hernandez, C., Kim, C., Zhao, J., Mysona, D., Bollinger, K.E., 2020. QuPath Automated Analysis of Optic Nerve Degeneration in Brown Norway Rats. TransI Vis Sci Technol 9, 22.

Pang, I.H., Clark, A.F., 2020. Inducible rodent models of glaucoma. Prog Retin Eye Res 75, 100799.

Reynaud, J., Cull, G., Wang, L., Fortune, B., Gardiner, S., Burgoyne, C.F., Cioffi, G.A., 2012. Automated quantification of optic nerve axons in primate glaucomatous and normal eyes-method and comparison to semi-automated manual quantification. Invest Ophthalmol Vis Sci $53,2951-2959$. 

Trakhtenberg, E.F., 2018. Single cell transcriptome profiling of retinal ganglion cells identifies cellular subtypes. Nat Commun 9, 2759.

Ritch, M.D., Hannon, B.G., Read, A.T., Feola, A.J., Cull, G.A., Reynaud, J., Morrison, J.C., Burgoyne, C.F., Pardue, M.T., Ethier, C.R., 2020. Axonet: A deep learning-based tool to count retinal ganglion cell axons. Scientific reports 10, 1-13.

Rodriguez, A.R., de Sevilla Muller, L.P., Brecha, N.C., 2014. The RNA binding protein RBPMS is a selective marker of ganglion cells in the mammalian retina. The Journal of comparative neurology 522, 1411-1443.

Salinas-Navarro, M., Mayor-Torroglosa, S., Jimenez-Lopez, M., Avilés-Trigueros, M., Holmes, T., Lund, R., Villegas-Pérez, M., Vidal-Sanz, M., 2009. A computerized analysis of the entire retinal ganglion cell population and its spatial distribution in adult rats. Vision research 49, 115126.

Sanchez-Migallon, M.C., Valiente-Soriano, F.J., Nadal-Nicolas, F.M., Di Pierdomenico, J., VidalSanz, M., Agudo-Barriuso, M., 2018. Survival of melanopsin expressing retinal ganglion cells long term after optic nerve trauma in mice. Exp Eye Res 174, 93-97.

Schlamp, C.L., Johnson, E.C., Li, Y., Morrison, J.C., Nickells, R.W., 2001. Changes in Thy1 gene expression associated with damaged retinal ganglion cells. Mol Vis 7, 192-201.

Schlamp, C.L., Montgomery, A.D., Mac Nair, C.E., Schuart, C., Willmer, D.J., Nickells, R.W., 2013. Evaluation of the percentage of ganglion cells in the ganglion cell layer of the rodent retina. Mol Vis 19, 1387-1396.

Schmitt, H.M., Schlamp, C.L., Nickells, R.W., 2016. Role of HDACs in optic nerve damageinduced nuclear atrophy of retinal ganglion cells. Neurosci Lett 625, 11-15.

Siliprandi, R., Canella, R., Carmignoto, G., Schiavo, N., Zanellato, A., Zanoni, R., Vantini, G., 1992. N-methyl-D-aspartate-induced neurotoxicity in the adult rat retina. Visual neuroscience 8 , 567-573.

Smith, R.S., Zabaleta, A., Kume, T., Savinova, O.V., Kidson, S.H., Martin, J.E., Nishimura, D.Y., Alward, W.L., Hogan, B.L., John, S.W., 2000. Haploinsufficiency of the transcription factors FOXC1 and FOXC2 results in aberrant ocular development. Hum Mol Genet 9, 1021-1032. Soto, I., Oglesby, E., Buckingham, B.P., Son, J.L., Roberson, E.D., Steele, M.R., Inman, D.M., Vetter, M.L., Horner, P.J., Marsh-Armstrong, N., 2008. Retinal ganglion cells downregulate gene expression and lose their axons within the optic nerve head in a mouse glaucoma model. J Neurosci 28, 548-561.

Teixeira, L.B., Buhr, K.A., Bowie, O., Duke, F.D., Nork, T.M., Dubielzig, R.R., McLellan, G.J., 2014. Quantifying optic nerve axons in a cat glaucoma model by a semi-automated targeted counting method. Mol Vis 20, 376-385.

Thomson, B.R., Souma, T., Tompson, S.W., Onay, T., Kizhatil, K., Siggs, O.M., Feng, L., Whisenhunt, K.N., Yanovitch, T.L., Kalaydjieva, L., Azmanov, D.N., Finzi, S., Tanna, C.E., Hewitt, A.W., Mackey, D.A., Bradfield, Y.S., Souzeau, E., Javadiyan, S., Wiggs, J.L., Pasutto, F., Liu, X., John, S.W., Craig, J.E., Jin, J., Young, T.L., Quaggin, S.E., 2017. Angiopoietin-1 is required for Schlemm's canal development in mice and humans. J Clin Invest 127, 4421-4436. Tolman, N.G., Balasubramanian, R., Macalinao, D.G., Kearney, A.L., MacNicoll, K.H., Montgomery, C.L., de Vries, W.N., Jackson, I.J., Cross, S.H., Kizhatil, K., Nair, K.S., John, S.W.M., 2021. Genetic background modifies vulnerability to glaucoma-related phenotypes in Lmx1b mutant mice. Dis Model Mech 14.

Tran, N.M., Shekhar, K., Whitney, I.E., Jacobi, A., Benhar, I., Hong, G., Yan, W., Adiconis, X., Arnold, M.E., Lee, J.M., Levin, J.Z., Lin, D., Wang, C., Lieber, C.M., Regev, A., He, Z., Sanes, J.R., 2019. Single-Cell Profiles of Retinal Ganglion Cells Differing in Resilience to Injury Reveal Neuroprotective Genes. Neuron 104, 1039-1055 e1012. 
Trantow, C.M., Mao, M., Petersen, G.E., Alward, E.M., Alward, W.L., Fingert, J.H., Anderson, M.G., 2009. Lyst mutation in mice recapitulates iris defects of human exfoliation syndrome. Investigative ophthalmology \& visual science 50, 1205-1214. Urcola, J.H., Hernandez, M., Vecino, E., 2006. Three experimental glaucoma models in rats: comparison of the effects of intraocular pressure elevation on retinal ganglion cell size and death. Exp Eye Res 83, 429-437.

Valiente-Soriano, F.J., Garcia-Ayuso, D., Ortin-Martinez, A., Jimenez-Lopez, M., GalindoRomero, C., Villegas-Perez, M.P., Agudo-Barriuso, M., Vugler, A.A., Vidal-Sanz, M., 2014. Distribution of melanopsin positive neurons in pigmented and albino mice: evidence for melanopsin interneurons in the mouse retina. Front Neuroanat 8, 131. Vickers, J.C., Schumer, R.A., Podos, S.M., Wang, R.F., Riederer, B.M., Morrison, J.H., 1995. Differential vulnerability of neurochemically identified subpopulations of retinal neurons in a monkey model of glaucoma. Brain Res 680, 23-35. Wang, A.Y., Lee, P.Y., Bui, B.V., Jobling, A.I., Greferath, U., Brandli, A., Dixon, M.A., Findlay, Q., Fletcher, E.L., Vessey, K.A., 2020. Potential mechanisms of retinal ganglion cell typespecific vulnerability in glaucoma. Clin Exp Optom 103, 562-571. Xiao, J., Lin, X., Qu, J., Zhang, J., 2021. Morphological and functional diversity of intrinsically photosensitive retinal ganglion cells. Synapse, e22200.

808 Zarei, K., Scheetz, T.E., Christopher, M., Miller, K., Hedberg-Buenz, A., Tandon, A., Anderson, M.G., Fingert, J.H., Abràmoff, M.D., 2016. Automated axon bounting in rodent optic nerve 
811 Fig. 1. Early loss of BRN3A+ RGCs in nee mice. (A) Representative images showing retinal 812 flat-mounts with BRN3A immunolabeling of RGC nuclei (green) and all TO-PRO-3 labeled 813 nuclei (blue) in nee and WT mice. Confocal images taken from the peripheral region of retinas; 814 scale bar $=50 \mu \mathrm{m}$. (B) Density plots of $B R N 3 A^{+}$RGC nuclei in nee (red) and WT (black) retinas 815 showed a significant loss in RGC density in 8-week-old and older nee mice. Note, some eyes in the 4- and 6-week groups were severely affected. (C) Average density of BRN3A- nuclei in nee retinas had an upward trend with increasing age, with a statistically significant difference at 15 weeks of age. (D) Plots of nuclear densities with data from B and $\mathrm{C}$ binned by age and additionally showing density of H\&E-detected nuclei. There was no difference in density of H\&E labeled nuclei between nee and WT retinas in the 4-8-week bin, even though these same retinas had a significant reduction in $\mathrm{BRN}_{3} \mathrm{~A}^{+}$nuclei; among nee retinas in the 12-15-week bin, the loss of $\mathrm{BRN}_{3} \mathrm{~A}^{+}$nuclei, off-set by an increase in $\mathrm{BRN}^{-} \mathrm{A}^{-}$nuclei, approximated the net change in nuclei detected with H\&E. n.s., not significant; ${ }^{*} p<0.05$; ${ }^{* \star} p<0.01$; ${ }^{* \star *} p<0.001$; ${ }^{* * * \star} p<0.0001$. 

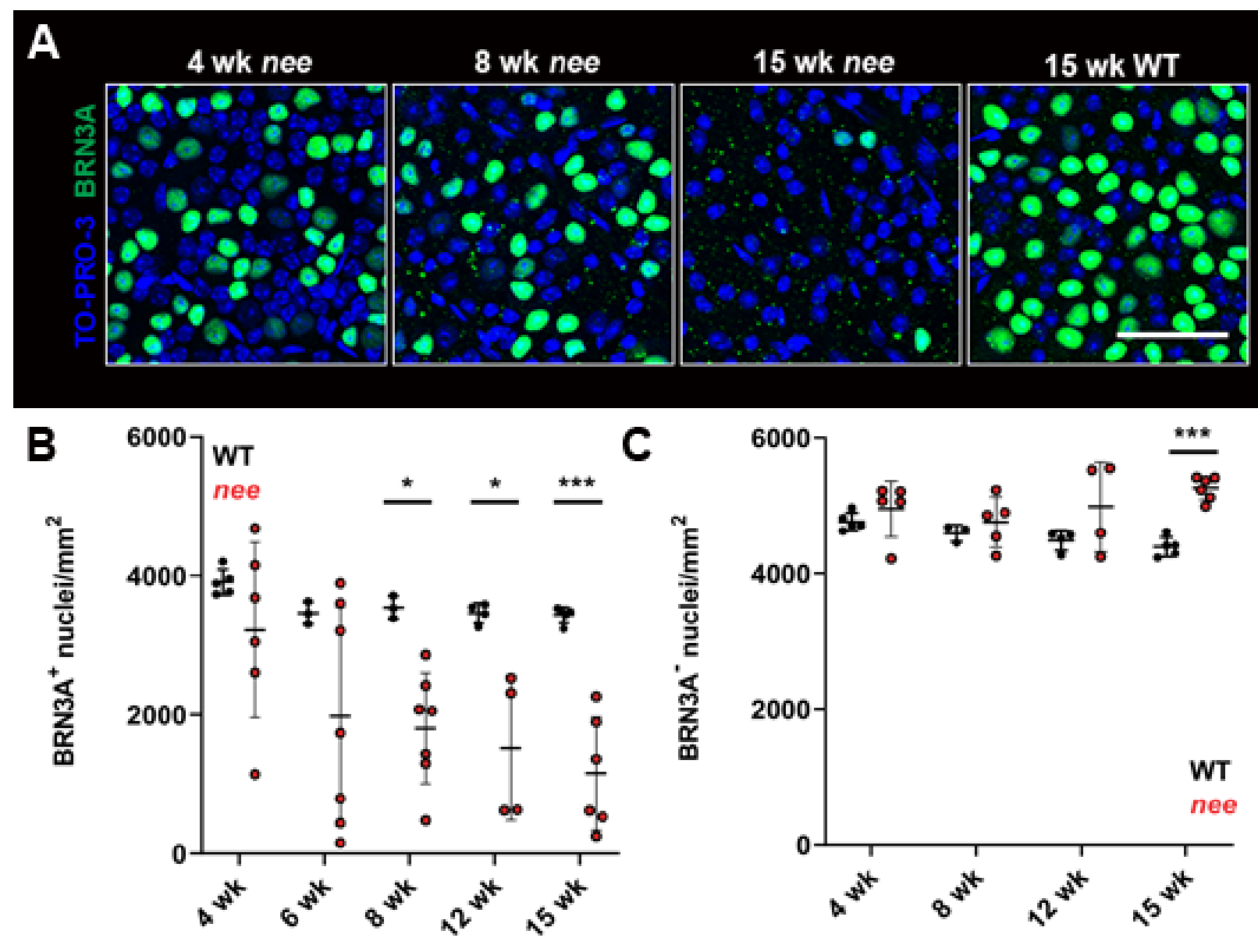

\section{5 wk nee}

15 wk WT

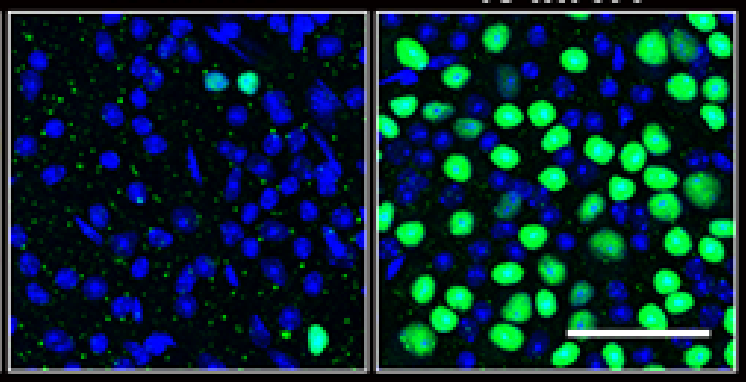

D

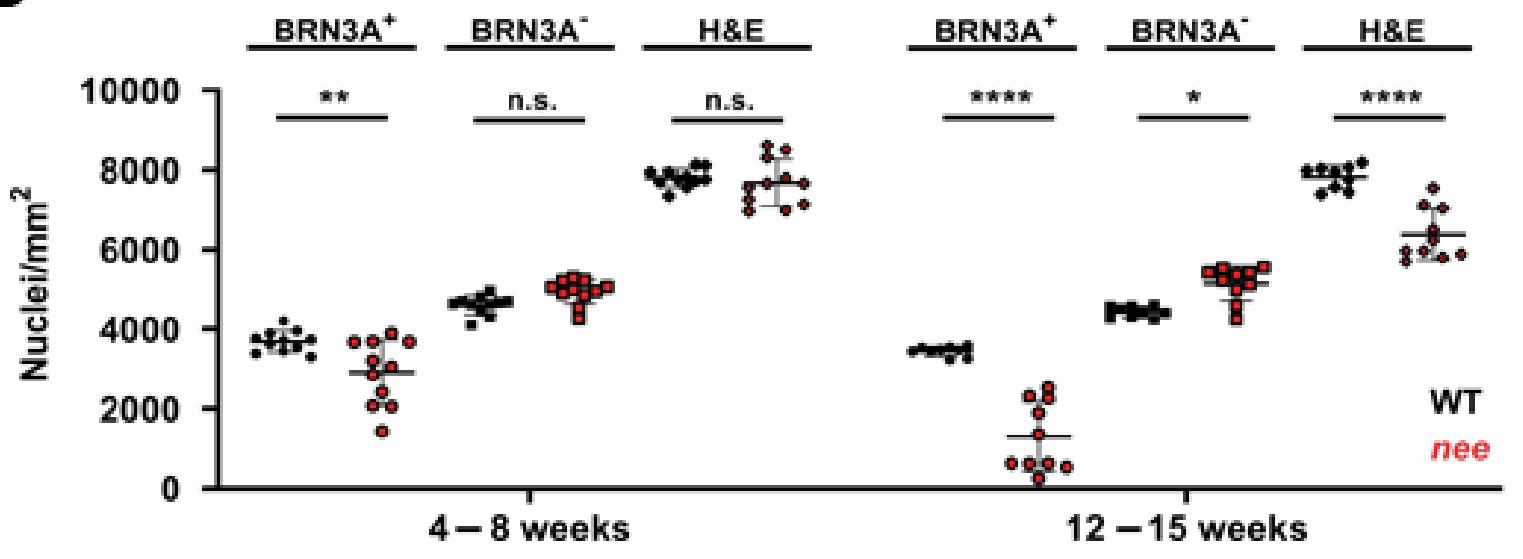



old nee mice. Representative images showing in vivo retinal optical coherence tomography from 8-week-old (A) WT and (B) nee mice. Note differences in the optic nerve head (ONH) region, the peripapillary retina (PPR) and the retinal ganglion cell complex (RGCC). (C) Plot of retinal ganglion cell complex thickness showing a statistically significant difference in 8-week-old non-mutant (WT and HET genotypes combined) and nee mice. Representative images are shown of an optic nerve cross-section with myelin staining by paraphenylenediamine (PPD) from 8-week-old (D) WT and (E) nee mice. Note the decreased axon density and increased PPD axoplasm staining in panel E compared to panel D. Scale bar $=10 \mu \mathrm{m}$. Plots of (F) optic nerve cross-sectional area and (G) optic nerve total axon counts showing a statistically significant differences between 8-week-old WT and nee mice. ${ }^{* *} \mathrm{p}<0.01 ;{ }^{* * *} \mathrm{p}<0.001$
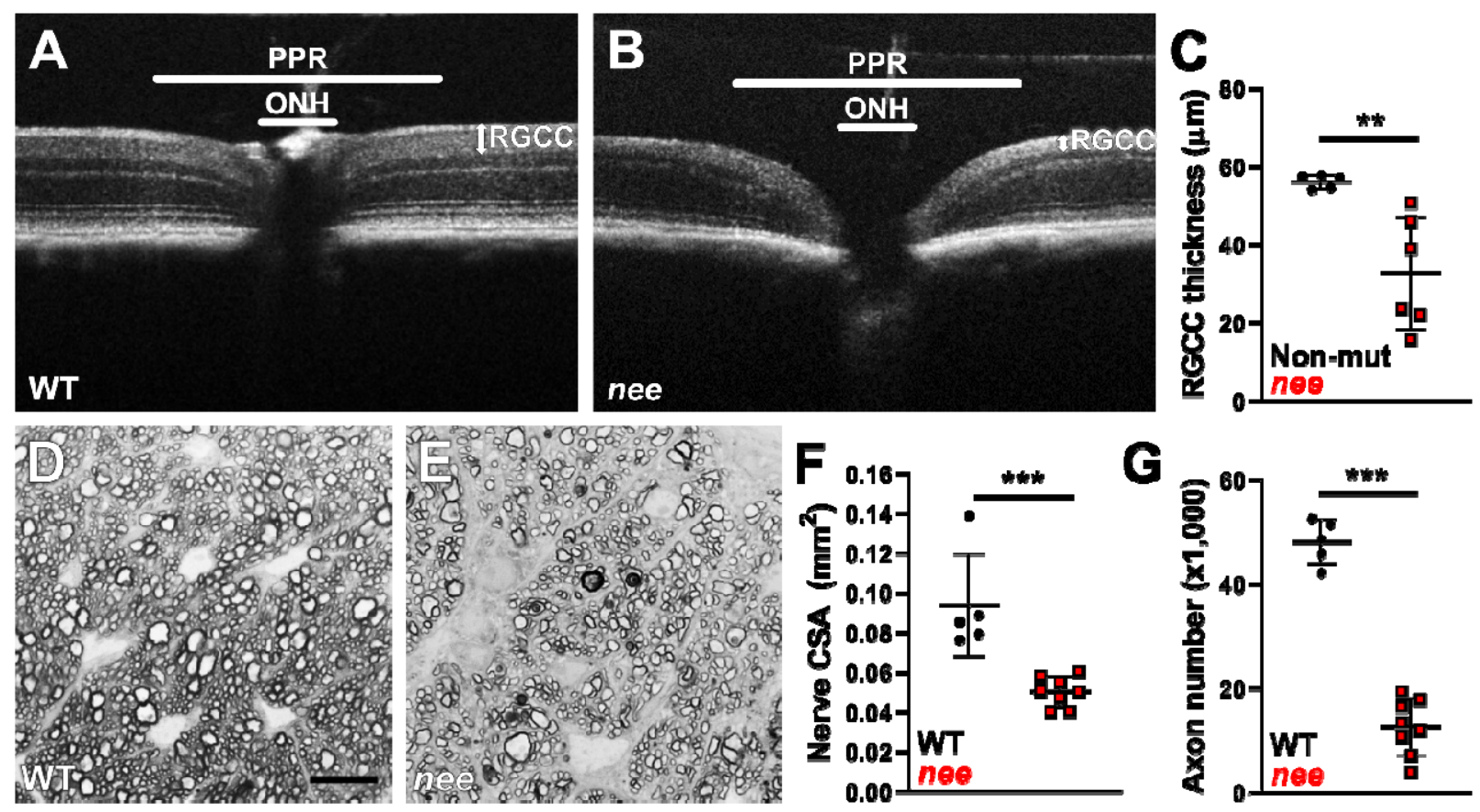
839 Fig. 3. Correlations between automatedly collected nuclei density and size metrics for

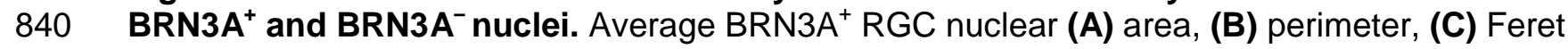

841 diameter, and (D) MinFeret diameter plotted as a function of average density for individual nee

842 and WT retinas. The BRN3A ${ }^{+}$RGC nuclei of $n e e^{\text {mod-sev }}$ retinas consistently showed significant

843 trends that nuclei size characteristics decrease with increasing severity of glaucomatous

844 damage. Average BRN3A- nuclear (E) area, (F) perimeter, (G) Feret diameter, and (H) MinFeret

845 diameter plotted as a function of average density for individual nee and WT retinas. Unlike

$846 \mathrm{BRN} \mathrm{A}^{+} \mathrm{RGC}$ nuclei, the nuclei of nee $\mathrm{mod-sev}$ retinas did not robustly show trends that nuclear

847 size characteristics change during glaucoma. WT (black circles); nee ${ }^{\text {mod-sev }}$ (red squares),

848 diseased nee retinas with BRN3A+ nuclei density < two SD compared to WT; nee ${ }^{\text {norm }}$ (red

849 circles), healthy nee retinas with $\mathrm{BRN}^{+} \mathrm{A}^{+}$nuclei density comparable to WT. 

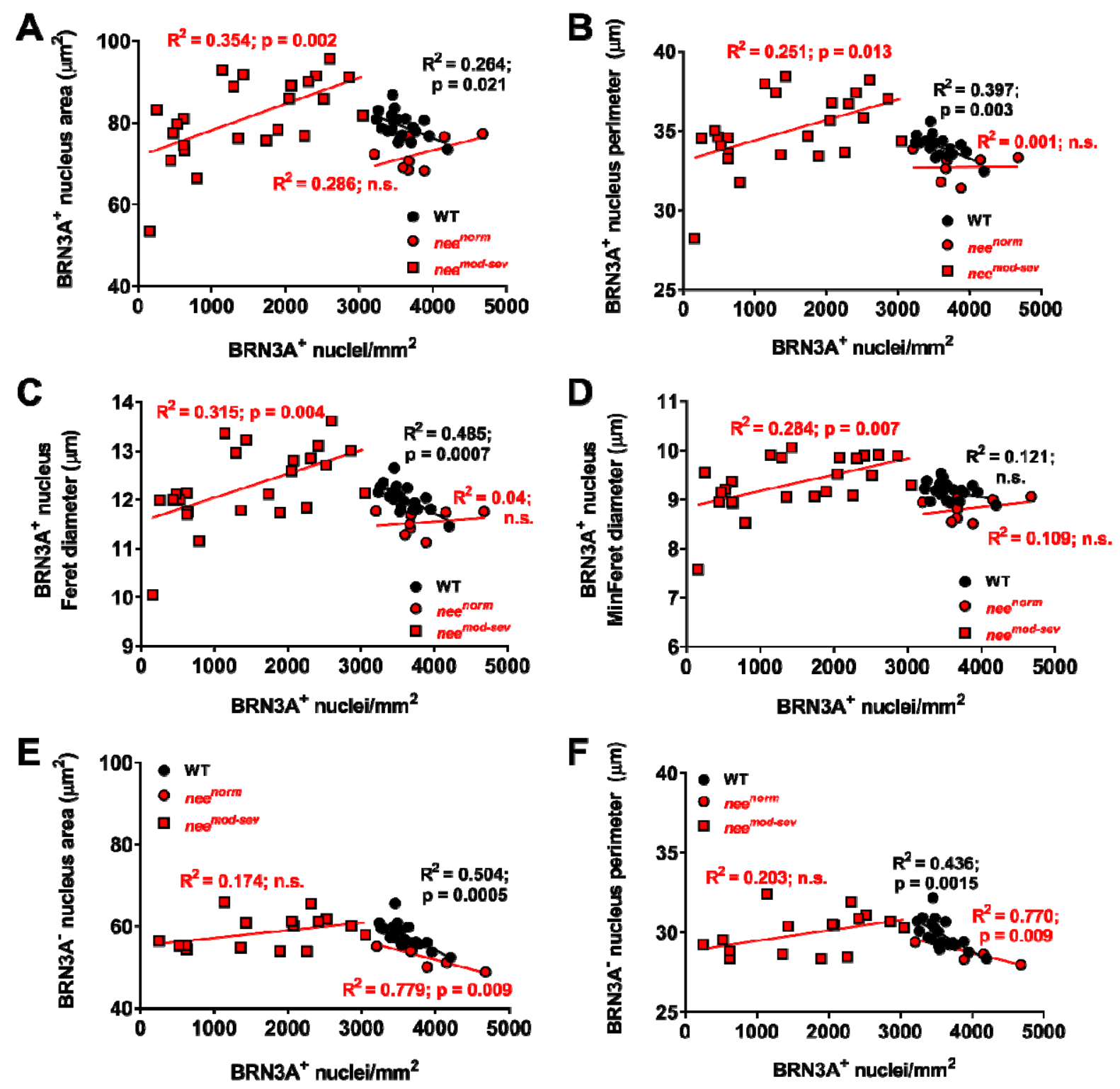

$\mathbf{F} \bar{\varepsilon}$
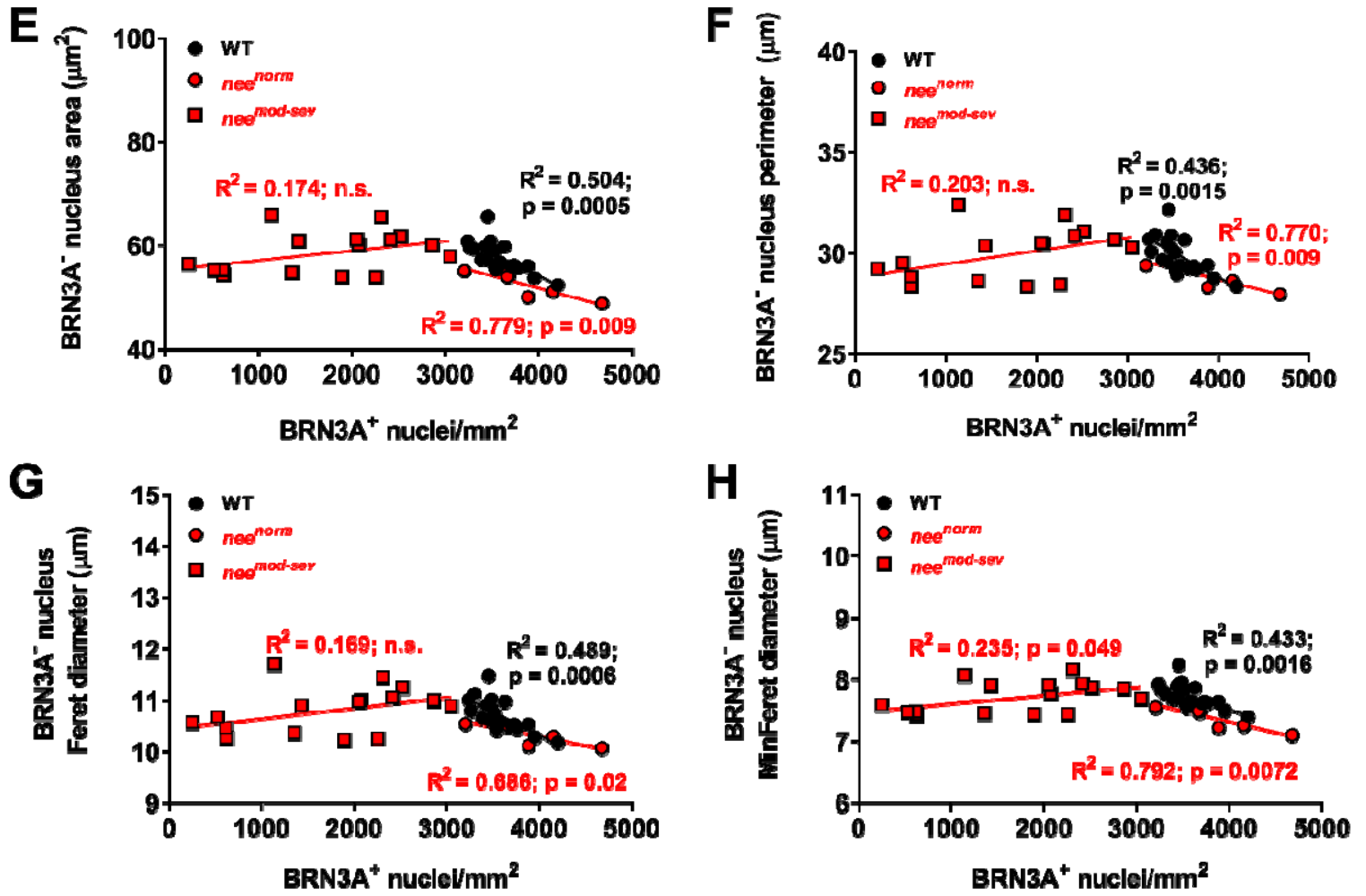
Fig. 4. Population distributions of nuclei size in nee $e^{\text {mod-sev }}$ retinas. (A) Average area of nuclei with data from all retinas aggregated by genotype. (B) Average area of nuclei with each retina individually plotted. Surviving BRN3A $A^{+} R G C$ nuclei in nee ${ }^{\text {mod-sev }}$ retinas (red) were on

855 average larger than WT (black). Note that many retinas with relatively modest RGC loss had an average nuclear size that was larger than WT; as glaucoma progressed the average size decreased. (C) Representative distribution curves for BRN3A+ nuclei, showing a WT retina (black arrowhead), a nee retina with modest disease (red arrowhead), and a nee retina with severe disease (red asterisk, in this instance data were combined from both retinas of a nee mouse in which both retinas had similar damage, increasing the number of nuclei analyzed to a number similar to the other examples). The same representative retinas are similarly indicated

862 in panels B, C, and E. Note that in modest disease, the distribution curve maintained a similar shape compared to WT, but was shifted to the right, indicating nuclear enlargement broadly occurring in most RGCs regardless of their initial size. In severe disease, the right-hand tail of the curve was attenuated and there was a corresponding reciprocal peak in the left-hand portion of the curve, indicating an increased proportion of small RGC nuclei relative to the total population. (D) Distribution curves for BRN3A- nuclei. (E) Box and whisker plot for each WT (grey) and $n e e^{\text {mod-sev }}$ (red) retina. To highlight differences in the shape of the distribution, data are normalized to the median value of nucleus size for each retina. Mean (black dot), median (solid line within each box), and percentile values (10th, 25th, 75th and 90th; vertical lines, black for WT and red for nee $e^{\text {mod-sev }}$ ) relative to the median. The average range of the distribution

872 between the 10th and 90th percentiles (shaded background) was displaced leftward in nee ${ }^{\text {mod-sev }}$

873 relative to WT. 
A

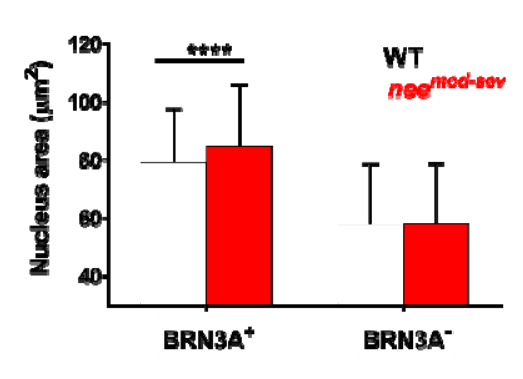

C

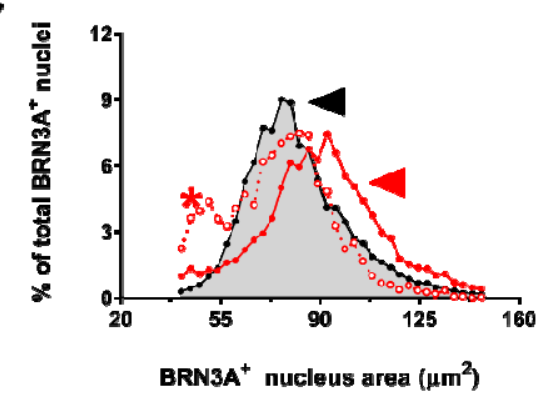

B

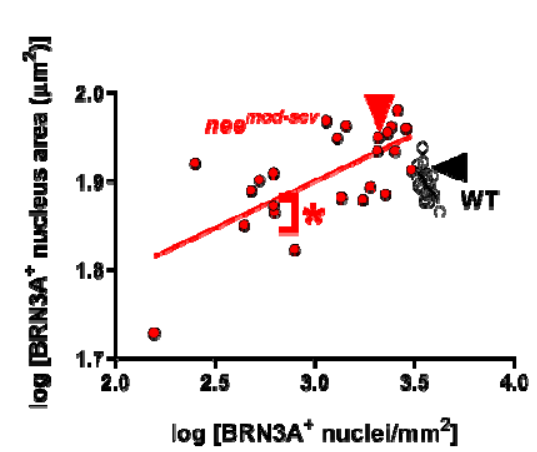

D

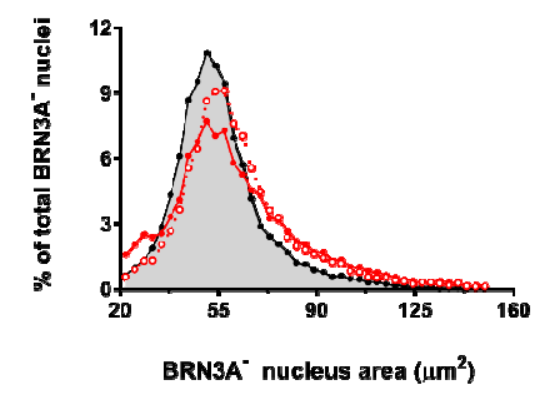

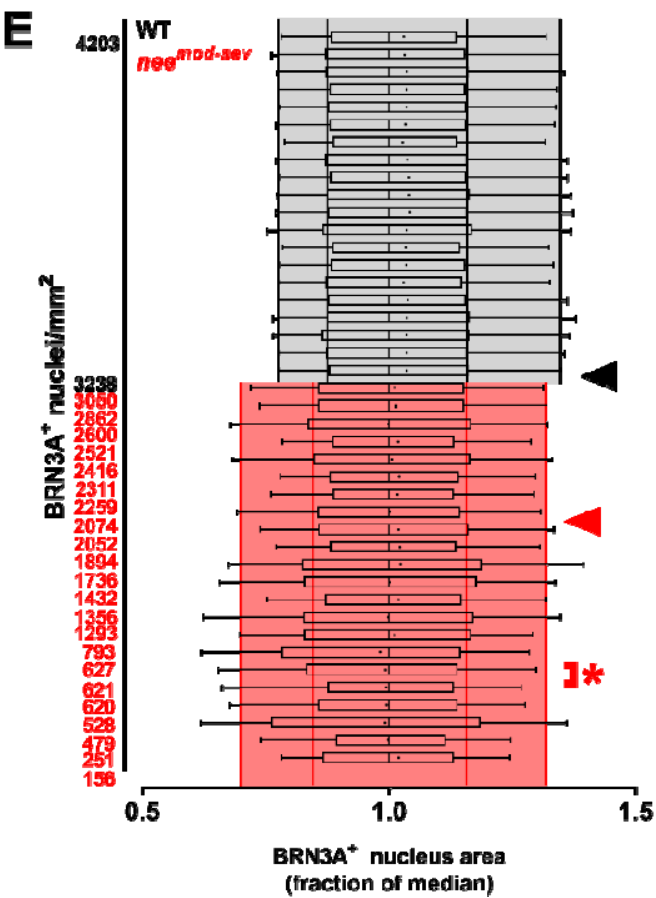


876 Supplementary Fig 1. Co-labeling of retinas with BRN3A and RBPMS. Manual absolute cell counts of sampling field images captured from the peripheral retina immuno-labeled with two different markers for retinal ganglion cells (RGCs) to compare the proportion of mono- and duallabeled cells in 6-wk-old nee vs. WT mice. Representative examples cropped from sampling fields of peripheral retina from a wild-type (WT, left column) and nee (right column) mouse with immunolabeling for (A-B) RBPMS (red) and (C-D) BRN3A (green), along with (E-F) nuclear staining by TO-PRO (blue) in composite view with merging of all channels. Scale bar $=50 \mu \mathrm{m}$.

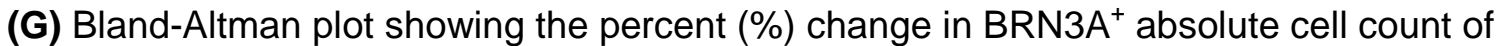
peripheral retina sampling fields (relative to $\mathrm{RBPMS}^{+}$) vs. the average absolute cell count of the two markers in the same sampling fields. Each dot represents a manual absolute cell count of a peripheral retina sampling field using both markers. For each genotype, the average \% change in $\mathrm{BRN}_{3} \mathrm{~A}^{+}$absolute cell counts of sampling fields are indicated by inset dotted lines and equations (average with standard deviation, $\mu \pm \sigma$ ) with distinct coloring that corresponds to each genotype. (H) Graph plotting manual absolute cell counts of BRN3A ${ }^{+}$vs. RBPMS ${ }^{+}$cells of the same fields ( $n=4$ fields per retina) from retinas of nee $(n=2$ mice) and WT controls $(n=3$ mice). Each dot represents the absolute cell count using both markers for a single sampling field. Within the graph, the solid line represents the best fit line and the flanking dotted curves indicate the $95 \%$ confidence interval for the data points. The coefficient of determination $\left(R^{2}\right)$ gives the proportion of variation in absolute cell count in a given sampling field between the two markers. Overall, a total of $n=6,012$ RBPMS $^{+}$(nee: $n=751$ cells, WT: $n=5,261$ cells) and 5,604 BRN3A ${ }^{+}$cells (nee: $n=611$ cells, WT: $n=4,993$ cells) were counted across a set of $n=$ 18 sampling fields from the peripheral retina (nee: $n=8$ fields, WT: $n=12$ fields). 

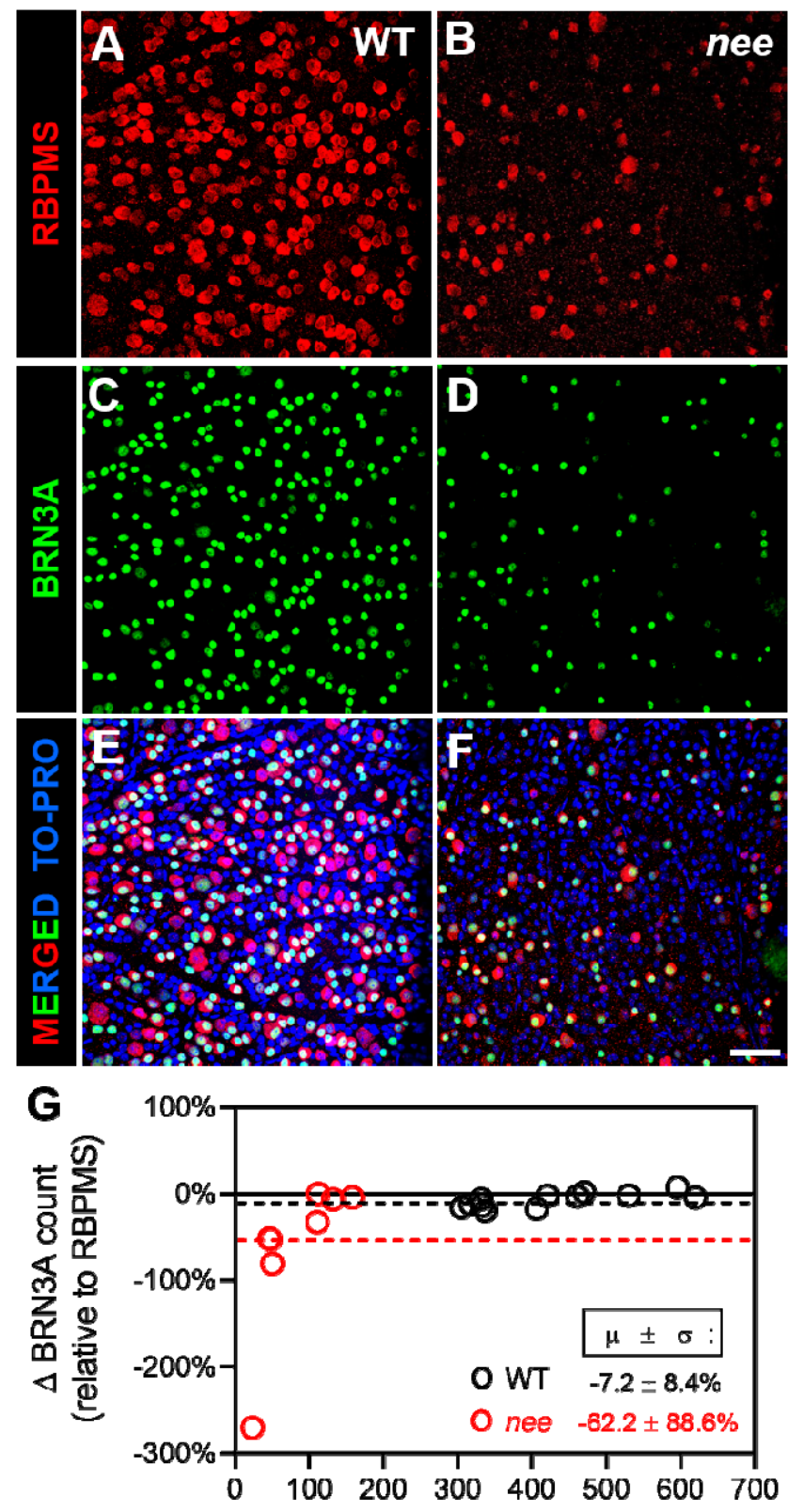

H

Average cell count (between markers)

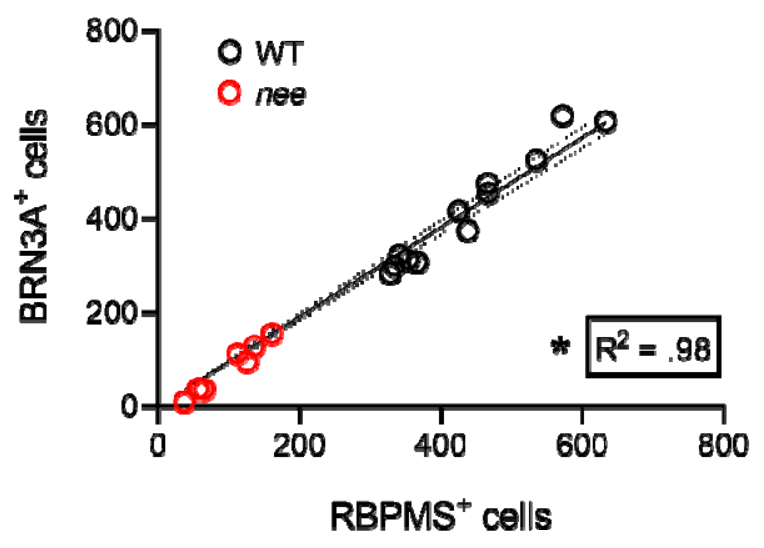

